\title{
Evaluation of the production planning policy alternatives in a PET resin production plant: A case study from Turkey
}

\author{
Abdullah Akman Demirkan¹, Zeynep Didem Unutmaz Durmuşoğlu² \\ ${ }^{1}$ Gaziantep University, Graduate School of Natural and Applied Sciences, Department of Industrial Engineering \\ ${ }^{2}$ Gaziantep University, Department of Industrial Engineering
}

How to cite: Demirkan, A.A., and Unutmaz Durmuşoğlu, Z.D. (2020), “Evaluation of the production planning policy alternatives in a PET resin production plant: A case study from Turkey", Brazilian Journal of Operations \& Production Management, Vol. 17, No. 2, e2020884. https://doi.org/10.14488/BJOPM.2020.024

\section{ABSTRACT}

Goal: The main purpose of this work is to develop several production planning models for one of bottle grade PET production plants (in Turkey) under different scenarios by considering different levels of inventory (no stock and different levels of safety stocks), different energy sourcing alternatives (natural gas/coal or both) and production throughput (different lot sizes).

Design/Methodology/Approach: Deterministic multi-product multi-period single level mixed integer linear programming model is presented. The model is implemented for the above defined scenarios. We have also considered the total emission produced for different energy alternatives.

Results: The models for the different scenarios have shown that significant performance improvements can be achieved by changing the parameters/policies of the production. The best model obtained has yielded $6.6 \%$ of profit improvement and $6.9 \%$ of cost reduction.

Limitations of the investigation: Planning horizon of this work could cover the data of years 2014 to 2018. However, the actual data employed for this study is limited with one year due to unavailability of further data. In addition to this, improvement of current production planning approach of the plant by implementation of proposed model is one of the objectives of this study to see success rate of model. Though, this couldn't be realized. We hypothetically tested the improvement provided by the proposed model, therefore we can't analyze the actual improvement.

Practical implications: Interactions among optimal results obtained by running model with different scenarios and their effect on selected performance variables are the main contribution of this work. Similar methodology could be used at other PET resin manufacturing plants or alternatively the production facilities having similar type of continuous manufacturing processes to find their optimal levels of inventory, production throughput and proper choice for energy sourcing alternative.

Originality/Value: The research on the production planning for PET resin industry by considering the different scenarios (levels of inventory / energy sourcing alternatives/ production throughput) is novel as far as we know, and therefore the approach used in this study is expected to be useful for other similar plants.

Keywords: PET Resin; Continuous Multi-grade Production; Production Planning; MILP; Capacitated Lot Sizing.

\section{INTRODUCTION}

Production planning can be defined as the planning of the resources (such as quantity of raw materials, human force, etc.) that will be transformed into products, by satisfying the customer requirements efficiently and economically (Tsutsumi et al., 2020; Valencia et al., 2019;

Financial support: None.

Conflict of interest: The authors have no conflict of interest to declare.

Corresponding author: a.akman.d@gmail.com

Received: 22 Aug 2019

Accepted: 10 May 2020

Editor: Osvaldo L. G. Quelhas 
Jang et al., 2020; Pochet, 2001) for a given period of time. The main goal of these plans are to find a way of balancing the tradeoff amongst economic targets (such as cost minimization or maximization of profit) and consumer satisfaction target (Pochet and Wolsey, 2006). It is not easy to achieve and maintain customer satisfaction. In order to realize this goal, the company must cope with different challenges. One of these challenges is the competition between other companies which are in the same market and offer common types of products and services (Cunha et al., 2018). This kind of competition forces companies to adjust both their production strategies regarding their resources and the planning of their operations (Liu et al., 2007). Distribution of resources to comply with orders and physical constraints such as plant capacity and storage facilities is the main challenge and a key to demand-driven operation (Tousain and Bosgra, 2006). Production plan have a critical role in the success of company, if it is efficient (Chan et al., 2015). The production management philosophies/approaches of a company can be easily seen in the production plans. If the plans are constructed based on no inventory we can understand that the approach is a variety of lean production even it is not referred corporately. Therefore, a production plan should always describe what the desired level of inventory and the throughput are. The production quantities which is known as lot sizing is determined to optimize some performance criteria (Karimi et al., 2003). This problem considers the tradeoff among the costs which share most of expenses generally (setup and inventory holding costs) to determine the least cost of a production plan for machines or production facilities in order to meet the demand for each item (Melega et al., 2018). Making the right decisions in lot sizing will affect directly the system performance and its productivity, which are important for a manufacturing firm's ability to compete in the market (Karimi et al., 2003). Problems could be solved for basic requirements (minimize cost, maximize profit) and much more complex cases. If a suitable lot sizing model which is determined to solve problematic issues could be developed and applied for a production facility, visible improvements could be seen soon. There would be economical, social and environmental benefits according to problem scope and obtained results.

There are numerous examples of real-world applications of lot sizing problems. Enormous savings in cost or increase in profit can be obtained with these practices. Plastics industry (and PET production as one of the plastics types) is among these areas. One of the applications on plastic industry is given in Van Wassenhove and De Bodt (1983). It is about injection moulding of a plastics production plant. Optimization of production in bottle grade PET resin plant is target of model considered in this study. Some of the recent studies on bottle grade PET resin are given in Liberopoulos et al. (2010) and in Hatzikonstantinou et al. (2012). Production scheduling of a PET resin plant according to defined quality range is argued on these articles. These kind of optimization activities are applied extensively in several corporations as a part of normal production or service process. The lot sizing problem can be handled as a different problem for continuous production like PET resin manufacturing while equivalent items requires no intermediate setups and this continuous sequence is called a lot (Brahimi, 2004). In this regard, we consider developing production planning alternatives under different scenarios for one of bottle grade PET production plants in Turkey (located in Gaziantep). This plant meets $47.5 \%$ of total bottle grade PET production amount of Turkey alone.

PET resin production process is a chemical production process based on conversion of raw materials and additives into end-products. In this regard, setups are the operations performed to changeover the grades which are very unlikely in the most manufacturing facilities. Grade changeovers are necessary to supply variety of products punctually, however these are undesirable because one changeover could cover excess time and it may causes high variability in end-product properties (Liberopoulos et al., 2010). It is apparent that the number of setups undesirably increases if there is not a suitable production plan. Even the setup itself is not considerably costly, these transitions (changeover creates a warm up period) results in production of second class products (they are sold with a lower price). In this respect, the production plan developed in this work considerably decreases the number of setups and this leads increase in revenue.

The main purpose of this work is to develop several production planning models for one of bottle grade PET production plants (in Turkey) under different scenarios by considering 
different levels of inventory (no stock and different levels of safety stocks), different energy sourcing alternatives (natural gas/coal or both) and production throughput (different lot sizes). We determined the system level objective as to maximize profit.

\section{LITERATURE REVIEW}

Lot-sizing is a part of production planning in which the production periods (or quantities) are fixed a priori according to placement of an order, or the setup, start-up, or changeover of a machine (Belvaux and Wolsey, 1998). Since there are various types of production systems, several authors classify the lot sizing problems according to system characteristics. Jans and Degraeve, (2008) classify the lot sizing problems consistent with their time scale, demand distribution and provided time horizon. Brahimi et al. (2017) extends this classification and consider the characteristics provided in Table 1. This classification enables the researchers to focus on a certain class of the problem. The performance of one type may not be same for another as shown by Florim et al. (2019).

In this paper, we use the classification approach of Brahimi et al. (2017) partially to identify the components of the system considered in this study. These components are as follows:

Table 1. Lot sizing problems: Main branches and parameters included in these branches

\begin{tabular}{cc}
\hline Parameter & Classifications \\
\hline $\begin{array}{c}\text { Information Degree } \\
\text { Horizon }\end{array}$ & $\begin{array}{c}\text { Deterministic, Stochastic } \\
\text { Finite, Infinite }\end{array}$ \\
\hline Time Scale & Discrete (Small or Large Time Periods), Continuous \\
Number of Items & $\begin{array}{c}\text { Single-item or Multi-item } \\
\text { Single-level or Multi-level }\end{array}$ \\
\hline $\begin{array}{c}\text { Resmber of Levels } \\
\text { Relevant Costs }\end{array}$ & $\begin{array}{c}\text { Setup related (Startup, Reservation), Inventory related (Holding, Backorder, } \\
\text { Lost sales), Capacity related (Regular hours, Overtime, Sub-contracting) } \\
\text { Sumber (Single-resource, Multi-resource), Type (Constant, Variable) }\end{array}$ \\
\hline Time Consuming & Demand satisfied on-time, Backorder, Lost sales, Sub-contracting \\
Activities & Setup time (ST) (minor or major ST), Processing time (Zero, Constant, \\
Variable), Lead Time, Transportation Time
\end{tabular}

Source: Brahimi et al. (2017).

Information Degree: This can be defined as if uncertainty is mentioned in models or not (Glock et al., 2014).

Horizon: Planning horizon can be defined as the time period which related problem determines (Díaz-Madroñero et al., 2014). It could be supposed to be variable, finite or infinite (Brahimi, 2004).

Time period/scale: There are two types; big time bucket problems and small time bucket problems. Small time buckets problems have short production periods like several hours. Big time bucket problems consist of longer time periods such as few days or weeks (Brahimi et al., 2006). The model considered in this work is a big bucket model while planning horizon is one year. Months are accepted as the discrete time periods.

Number of products and number of levels: There are two types for these class; singleitem or multi-item and single level or multi-level. Single-level and multi-level problems is considered based on production stages (Díaz-Madroñero et al., 2014). The problem given in this paper consists of multi item products (there are three end-products) while production line is single level (the chemical reaction is a continuous process and there is no assembly). The details of solution approaches to this type are not given here due to space limitations. For details, readers are suggested to see: Bahl et al. (1987); Karimi et al. (2003); Jans and Degraeve (2008); Buschkühl et al. (2010); Díaz-Madroñero et al. (2014). 
Relevant costs: These include three types of costs: Setup related costs, Inventory related costs and Capacity related costs. Setup related costs linked to setups on production facility. This cost type can be defined as different variations according to model (start-up cost, reservation cost). Inventory related costs include holding costs (generally referred as the costs of capital equivalent to specified inventory quantity), shortage costs (backlog costs) and lost sales. Capacity related costs are related to using different capacity levels (normal or additional). Production throughput is directly associated with manpower generally, so if capacity changes workforce level must change to balance requirements (overtime costs, subcontracting costs, hiring/firing costs) (Brahimi, 2004). The details of solution approaches to this type are not given here due to space limitations. For details, readers are suggested to see: Brahimi (2004), Jans and Degraeve (2008), Brahimi et al. (2017).

Resource constraints/capacities: This type of problems refer to the capacities of the available resources in the production system. Restrictions of available resources could determine how production process must be designed. These kind of constraints may increase the complexity of the production planning models, but enable more realistic models. Constraints related to inventory limitations, supply of parts and raw materials from suppliers, productive resources such as machines and workforce and transportation resources are identified among these (Díaz-Madroñero et al., 2014). Model considered in this study is capacitated. The most important constraint of our model is production capacity constraint. There are certain unit consumption of raw and additive materials for producing one unit of end-product and these figures used as unit consumption parameters on model. Resources used in model (raw material, additive material, utility and energy resources) are limited by maximum production and processing capacity. Productive resource limitation is related with maximum production and processing capacity. The details of solution approaches to this type are not given here due to space limitations. For details, readers are suggested to see: Sung and Chang (1986); Drexl and Haase (1995); Hung and Hu (1998); Karimi et al. (2006); Brandimarte (2006); Erromdhani and Rebaï (2017).

Service Policy: To make the models more realistic, several extensions related to demand can be identified (Díaz-Madroñero et al., 2014). Both single-item and multi-item problems with backlogging extension are reviewed in Küçükyavuz and Pochet (2009). Multi-item problem with backlogging extension is examined in (Karimi et al., 2006). Backlogging with safety stock for an uncapacitated model is given in Loparic et al. (2001). In this work, we have used the service level variable as defined by (Boulaksil, 2016).

Nature of demand: Demand is one of the typical parameters of production planning models. If demand levels are known exactly, it is called deterministic, otherwise it can be termed stochastic (Díaz-Madroñero et al., 2014). Demand is assumed as deterministic on the model considered in this study. The demand is forecasted by considering the data of the previous year.

Time Consuming Activities: These include transportation time, lead time, setup time, processing time per unit, and production speed (Brahimi, 2004). According to problem scope, one or more of these defined activities can be used in model.

Objectives: Objectives can be varied consistent with problem and model. There can be single objective or multiple objectives. Maximizing profit and minimizing total cost are among the most common objectives mentioned in literature. Different objectives based on maximization or minimization can be defined (maximizing service level, minimizing environmental impact etc.). Other different possible objectives are not given here due to space limitations. For details, readers are suggested to see: (Williams, 2013).

\section{PROBLEM DEFINITON AND METHODOLOGY}

PET resin production process is based on conversion of additives and raw materials toward end-products by chemical reactions. Production process is basically a chemical production process; hence production logic is different from traditional MRP. There are certain unit consumption rates of raw and additive materials (consumption quantity per one ton of 
end product) for producing different end-products. Average unit consumption rate for utility resources and average unit carbon emission generation rate are derived from the actual production data of previous year. Carbon emission is also calculated to show the direct effect of energy alternatives.

We should introduce to products of this production plant before going into details. The plant produces three different grades of end-products: $0.76 \mathrm{IV}, 0.80 \mathrm{IV}$ and $0.84 \mathrm{IV}$. The main difference between these end-products is the value of intrinsic viscosity (IV). IV is linked with the length of the polymer chains. If the IV value increases, the polymer chain length increases, and as a result, the end-product hardness rises (Liberopoulos et al., 2010). $0.76 \mathrm{IV}$ grade of product is primarily used for water bottles. $0.80 \mathrm{IV}$ and $0.84 \mathrm{IV}$ grade of products are used for carbonated soft drink bottles. In this paper, these quality variants are named as "grade of the product".

Unit prices and purchase costs are calculated by considering the average values of 2016 production. We assume there is no inflation or price fluctuation. Two main raw materials, four additive materials and three utility resources (electricity/cooling water/energy resource) are considered in the model.

As mentioned earlier in the introduction section, we have implemented our models under different scenarios. Initially, we have considered three different energy alternatives; natural gas/ coal / both (equally weighted). The second type of scenarios considers different capacity alternatives. We have used numerous capacity alternatives starting from the possible minimum (600 tons/day) to possible maximum (725 tons/day). We have changed the constraints in our model to show the different alternatives. It has been realized that, it is essential to keep the production rate between 655 tons/day and 725 tons/day not to face with backlogs.

The third type of scenarios is based on different stock policies. It is known fact that, excess production is seen as one of the resources of waste and less stock (if possible zero stock) has been a desirable policy solution in most of the production systems (Hofer et al., 2012). On the other hand, it is nearly impossible to forecast the exact demand and we could have serious backlogging cost in the peak time of demand. Subsequently, it is becomes a logical alternative to keep the stocks in a rational level. It can be stated that there is a tradeoff between expected service level by safety stocks and inventory holding cost. Optimum inventory policy must balance these two points (Rădăşanu, 2016). In our work, we have used the Equation (1) to calculate the safety stock. The Equation (1) is known to be a good option if there is deterministic replenishment time and stochastic consumption rate.

Safety Stock $=\sigma_{D} * S F * \sqrt{\left(\frac{L T}{T}\right)}$

where:

$\sigma_{D}$ : Standard deviation of demand;

SF: Service level factor;

LT: Lead time;

$\mathrm{T}$ : Time used to calculate standard deviation of demand.

SF (z score) is found from standard normal distribution table along with expected service level percentage.

Safety stock calculations are based on the demand predictions obtained with ARIMA method. Three alternatives are designated for different safety stock policies. We have assumed three different service level rates (the measure of the meeting the demand) for safety stock calculations. Since customers demand different products among all, we have calculated the share of product types (product 1, 2 and 3) among all sales for the years between 2014 and 2016 as depicted in Table 2. 
We assume that the share of demand for each product type will be the average rates given in Table 2 for our model. In the first and the second alternatives, we plan to meet the $90 \%$ and $95 \%$ of customer demands (service levels) equally for all product types. Even we know that higher service level is more desirable it also increases the inventory holding cost. Therefore, we have created the third alternative (hybrid) to meet the demand \%95, \%85 and \%90 for types 1, 2 and 3 respectively as previously done by Rădăşanu, (2016).

Table 2. The demand distribution (share in total) by the product types (2014-2016)

\begin{tabular}{ccccc}
\hline \multirow{2}{*}{ Year } & \multicolumn{4}{c}{ Demand Rate For All Production Grades } \\
\cline { 2 - 5 } & \multicolumn{4}{c}{ Product Types } \\
\cline { 2 - 5 } 2014 & $\mathbf{0 . 7 6}$ IV (Product 1) & $\mathbf{0 . 8 0}$ IV (Product 2) & $\mathbf{0 . 8 4}$ IV (Product 3) & Total \\
2015 & $58.5 \%$ & $17.4 \%$ & $24.1 \%$ & $100 \%$ \\
2016 & $56.8 \%$ & $9.0 \%$ & $34.3 \%$ & $100 \%$ \\
Average Rate & $58.5 \%$ & $11.3 \%$ & $30.1 \%$ & $100 \%$ \\
\hline Supposed Service Level & $57.9 \%$ & $12.6 \%$ & $29.5 \%$ & $100 \%$ \\
\hline
\end{tabular}

Source: The authors themselves.

We use the mixed integer linear programming to solve the problem defined in this work. Modeling lot sizing problems with mixed integer programming with some extensions of original problem (start-up, changeover, number of setups) is given in Belvaux and Wolsey (2003). Different cases from chemical industry using MILP is mentioned in Kallrath (2000) and Kallrath (2002). While resources for production are limited in our case, we can categorize our model as capacitated. Since, the resin production takes place in one stage, we classify our model as a single-level problem. Problem types, extensions and different cases of production planning by using MIP can be seen in (Pochet and Wolsey, 2006). In addition, we define some performance variables to measure success of model implementation. These criteria are widely used both in academic studies and on an industrial scale. Critical success factors for project and process management is reviewed by (Ferreira et al., 2019) and key parameters for the analysis stage of operations is reviewed by (Grillo et al., 2018). Although focal points of these articles are different from this paper, a similar reasoning has been done.

The model components are as provided in the subtitles below:

\section{Defined sets}

The product types (IV grade) are represented with 'J'. The unit time is accepted as one month. Time variable is represented with ' $T$ '. Sets are as given in Table 3.

Table 3. Sets of model

\begin{tabular}{cc}
$\mathrm{J}$ & Grade of the product, indexed by $\mathrm{j}_{1} \mathrm{~J}=\{1,2,3\} \equiv\{0.76,0.80,0.84\}$ \\
\hline $\mathrm{T}$ & Time (Month), indexed by $\mathrm{t}, \mathrm{T}=\{1,2,3,4,5,6,7,8,9,10,11,12\}$ \\
\hline
\end{tabular}

Source: The authors themselves.

\section{Model parameters}

Demand, safety stock and $\mathrm{M}$ value (is considered as a big number) are as given in Table 4. Unit cost and prices are given in Table 5. Unit raw material usage (consumption) parameters

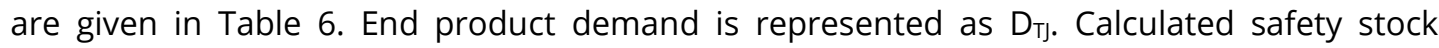
quantity is represented as $\mathrm{SS}_{\mathrm{T} \text { J. }} \mathrm{M}$ value is maximum monthly production amount in model.

TABLE 4. PARAMETERS-1

\begin{tabular}{cc}
\hline$D_{T \mathrm{~J}}$ & Production demand per period, $t \in T, j \in J$ \\
\hline$S S_{T \mathrm{~J}}$ & Safety stock per period, $t \in T, j \in J$ \\
\hline
\end{tabular}




\begin{tabular}{ll}
\hline M & Very big number \\
\hline Source: The authors themselves. &
\end{tabular}

Source: The authors themselves.

Table 5. Parameters-2 / Unit cost and prices

\begin{tabular}{cc}
\hline REV & Sales price \\
\hline$C_{F}$ & Fixed setup cost \\
\hline$C_{P}$ & Production unit cost \\
\hline$C_{S S P L}$ & Safety stock overstock deficit unit cost \\
\hline$C_{S S M 1}$ & Safety stock shortage deficit unit cost \\
\hline$C_{B}$ & Backlog penalty unit cost \\
\hline$C_{R 1}$ & Raw material-1 unit purchase cost \\
\hline$C_{R 2}$ & Raw material-2 unit purchase cost \\
\hline$C_{A D D 1}$ & Additive material-1 unit purchase cost \\
\hline$C_{A D D 2}$ & Additive material-2 unit purchase cost \\
\hline$C_{A D D 3}$ & Additive material-3 unit purchase cost \\
\hline$C_{A D D 4}$ & Additive material-4 unit purchase cost \\
\hline$C_{U 1}$ & Utility-1 unit cost \\
\hline$C_{U 2}$ & Utility-2 unit cost \\
\hline$C_{U 3}$ & Utility-3 unit cost \\
\hline
\end{tabular}

Source: The authors themselves.

Table 6. Parameters-3 / Unit consumption rates of required materials

\begin{tabular}{|c|c|}
\hline $\operatorname{ResR}_{1}$ & Consumption of raw material- 1 per one unit of product j \\
\hline $\operatorname{ResR}_{2}$ & Consumption of raw material-2 per one unit of product $j$ \\
\hline $\operatorname{ResADD}_{1}$ & Consumption of additive material- 1 per one unit of product $j$ \\
\hline $\operatorname{Res} \mathrm{ADD}_{2}$ & Consumption of additive material- 2 per one unit of product $j$ \\
\hline $\operatorname{ResADD}_{3}$ & Consumption of additive material-3 per one unit of product $j$ \\
\hline $\operatorname{ResADD}_{4}$ & Consumption of additive material- 4 per one unit of product $j$ \\
\hline $\mathrm{ResU}_{1}$ & Consumption of utility-1 per one unit of product j \\
\hline $\mathrm{ResU}_{2}$ & Consumption of utility- 2 per one unit of product $j$ \\
\hline $\mathrm{ResU}_{3}$ & Consumption of utility-3 per one unit of product $j$ \\
\hline $\mathrm{COE}_{\mathrm{P}}$ & Generation of carbon emission as t per one unit of product $j$ \\
\hline
\end{tabular}

Source: The authors themselves.

\section{Raw material consumption variables}

Variables representing the consumption of required materials (raw materials, additive materials and utility resources) are as given in Table 7. Total material consumption and total material cost is calculated by using these variables.

Table 7. Raw material consumption variables

\begin{tabular}{cl}
\hline ResRaw1 $_{\mathrm{T}}$ & Raw material-1 usage per period, $\mathrm{t} \in \mathrm{T}, \mathrm{j} \in \mathrm{J}$ \\
\hline ResRaw2 $_{\mathrm{TJ}}$ & Raw material-2 usage per period, $\mathrm{t} \in \mathrm{T}, \mathrm{j} \in \mathrm{J}$ \\
ResAdd1 $_{\mathrm{T}}$ & Additive material-1 usage per period, $\mathrm{t} \in \mathrm{T}, \mathrm{j} \in \mathrm{J}$ \\
\hline ResAdd2 $_{\mathrm{TJ}}$ & Additive material-2 usage per period, $\mathrm{t} \in \mathrm{T}, \mathrm{j} \in \mathrm{J}$ \\
ResAdd $_{\mathrm{T}}$ & Additive material-3 usage per period, $\mathrm{t} \in \mathrm{T}, \mathrm{j} \in \mathrm{J}$ \\
\hline ResAdd4 $_{\mathrm{T}}$ & Additive material-4 usage per period, $\mathrm{t} \in \mathrm{T}, \mathrm{j} \in \mathrm{J}$ \\
\hline ResUti1 $_{\mathrm{T}}$ & Utility-1 consumption per period, $\mathrm{t} \in \mathrm{T}, \mathrm{j} \in \mathrm{J}$ \\
ResUti2 $_{\mathrm{TJ}}$ & Utility-2 consumption per period, $\mathrm{t} \in \mathrm{T}, \mathrm{j} \in \mathrm{J}$ \\
\hline ResUti3 $_{\mathrm{TJ}}$ & Utility-3 consumption per period, $\mathrm{t} \in \mathrm{T}, \mathrm{j} \in \mathrm{J}$ \\
ByProdEmission & Carbon emission generation per period, $\mathrm{t} \in \mathrm{T}, \mathrm{j} \in \mathrm{J}$ \\
\hline
\end{tabular}

Source: The authors themselves. 


\section{Decision variables}

Decision variables used in our model is given in Table 8. In addition to the commonly used variables such as production quantity, inventory quantity and binary variable; backlog quantity, utilization rate and service level are added in model in order to show the operational efficiency. Safety stock overstock, safety stock shortage and safety stock variation variables are added to model for modified inventory equation.

Table 8. Decision variables

\begin{tabular}{|c|c|}
\hline $\mathrm{X}_{\mathrm{T}}$ & Production in period t by grade $\mathrm{j}, \mathrm{t} \in \mathrm{T}, \mathrm{j} \in \mathrm{J}$ \\
\hline $\mathrm{S}_{\mathrm{TJ}}$ & Net inventory in period $t$ by grade $j, t \in T, j \in J$ \\
\hline SSPLT & Safety stock overstock in period t by grade $j, t \in T, j \in J$ \\
\hline $\mathrm{SSMI}_{\mathrm{T}}$ & Safety stock shortage in period $t$ by grade $j, t \in T, j \in J$ \\
\hline $\mathrm{DSS}_{\mathrm{T}}$ & Safety stock variation in period $t$ by grade $j, t \in T, j \in J$ \\
\hline $\mathrm{B}_{\mathrm{T}}$ & Backlog in period t by grade $\mathrm{j}, \mathrm{t} \in \mathrm{T}, \mathrm{j} \in \mathrm{J}$ \\
\hline UTIL & Average utilization rate in period $t$ by grade $j, t \in T, j \in J$ \\
\hline$S L_{T}$ & Average service level in period t by grade $\mathrm{j}, \mathrm{t} \in \mathrm{T}, \mathrm{j} \in \mathrm{J}$ \\
\hline $\mathrm{Y}_{\mathrm{TJ}}$ & Binary variable in period $t$ by grade $j, t \in T, j \in J$ \\
\hline
\end{tabular}

Source: The authors themselves.

\section{Objective function}

The main objective is to maximize the total profit. Objective function (given in Equation 3) is simply the subtraction of total cost from total revenue.

$\max \sum_{1}^{T} \sum_{1}^{J}\left(R e v * X_{T J}\right)-\left(\sum_{1}^{T} \sum_{1}^{J}\left(S S P L_{T J} * C_{S S P L}+S S M I_{T J} * C_{S S M I}+B_{T J} * C_{B}+Y_{T J} * C_{F}+X_{T J} * C_{P}+\right.\right.$ $\operatorname{ResRaw} 1_{T J} * C_{R 1}+\operatorname{ResRaw} 2_{T J} * C_{R 2}+\operatorname{Res} A d d 1_{T J} * C_{A D D 1}+\operatorname{ResAdd} 2_{T J} * C_{A D D 2}+\operatorname{Res} A d d 3_{T J} *$ $\left.C_{A D D 3}+{\operatorname{Res} A d d 4_{T J}} C_{A D D 4}+\operatorname{ResUti1_{TJ}} * C_{U 1}+\operatorname{ResUti2}_{T J} * C_{U 2}+\operatorname{ResUti3}_{T J} * C_{U 3}\right)$ (3)

\section{Equations and constraints}

Equation (4) shows that production quantity cannot exceed upper boundary as symbolized as 'big $\mathrm{M}^{\prime}$ ' value. Production depends on production decision as per planned demands. If production occurs in that period by grade $j$ the binary variable takes the value of 1 , otherwise it is equal to 0 .

$X_{T J} \leq M * Y_{T J} \quad \forall j \in J, \forall t \in T$

Equation (5) and (6) express the monthly upper bounds for production. Production quantity cannot surpass maximum bound. $M$ value is equal to maximum bound.

$X_{T J} \leq M \quad \forall j \in J, \forall t \in T$

Equation (7) and (8) expresses monthly and annual (or sum of related periods) limits of production capacity. Equation (7) is the constraint for monthly production, Equation (8) is for all production in all of the periods in planning horizon.

$\sum_{l}^{T} X_{T J} \leq$ Max Monthly Production Capacity $\quad \forall j \in J, \forall t \in T$ 
Equation (9) and (10) shows that at the start of the first period there is no product inventory and backlog. Equation (11) expresses annual (or sum of related periods) boundary of inventory quantity. Maximum storage capacity depends on the availability of space in the storage area and storage silos.

$$
\begin{aligned}
& S_{T J}=0, T=1 \quad \forall j \in J \\
& R_{T J}=0, T=1 \quad \forall j \in J \\
& \sum_{1}^{T} \sum_{1}^{J} S_{T J} \leq \text { Max Storage Capacity } \quad \forall j \in J, \forall t \in T
\end{aligned}
$$

Equation (12) shows inventory balance equation.

$S S P L_{T-1, J}-S S M I_{T-1, J}+B_{T J}+X_{T J}=D_{T J}+D S S_{T, J}+S S P L_{T, J}-S S M I_{T, J} \forall j \in J, \forall t \in T$

Equation (13) shows net inventory. Equation (14) shows safety stock variation. Constraints (15) and (16) expresses that demand must be greater than backlog quantity and safety stock must be greater than safety stock shortage quantity.

$$
\begin{array}{ll}
S_{T J}=S S P L_{T J}+S S_{T J}-S S M I_{T, J} & \forall j \in J, \forall t \in T \\
D S S_{T J}=S S_{T, J}-S S_{T-1, J} & \forall j \in J, \forall t \in T \\
D_{T, J} \geq B_{T, J} & \forall j \in J, \forall t \in T \\
S S_{T, J} \geq S S M I_{T, J} & \forall j \in J, \forall t \in T
\end{array}
$$

Equation (17) shows total utilization rate. Service level percentage is shown in equation (18). Equation (19) shows total number of setup times.

Constraint (20) shows non-negativity restrictions on the variables. Constraint (21) shows binary restriction on binary variable.

$$
\begin{aligned}
& U T I L_{T, J}=\left(\frac{\sum_{l}^{T} \sum_{l}^{J} X_{T, J}}{\text { Max Production Capacity }(\text { Total Number of Periods })}\right) * 100 \quad \forall j \in J, \forall t \in T \\
& S L_{T, J}=100-100 *\left(\frac{B_{T, J}}{D_{T, J}}\right) \quad \forall j \in J, \forall t \in T \\
& \text { TOTSETUP } P_{T, J}=\sum_{I}^{T} \sum_{l}^{J} Y_{T, J} \quad \forall j \in J, \forall t \in T \\
& X_{T J}, S_{T J}, S S P L_{T, J}, S S M I_{T, J}, R_{T J} \geq 0 \quad \forall j \in J, \forall t \in T \\
& Y_{T J} \in\{0,1\} \quad \forall j \in J, \forall t \in T
\end{aligned}
$$




\section{RESULTS AND DISCUSSION}

\section{Implementation of model}

A comparative study is conducted by considering three different factors (inventory, capacity and energy) with different levels (policies) as presented in Table 9. Demand data is extracted from forecasted demand data for all grades of products for 2017. Inventory policy consists of different safety stock decisions which are determined according to the supposed service levels. Capacity policy depends on changing variables when capacity increases regularly. Energy policy is defined according to the selected energy source.

The proposed model in this study was written in GAMS. CPLEX which is integrated with GAMS ( $v$ 23.5) was used as the solver. We attempted to solve our models with different solvers, however we have chosen the CPLEX due to its significant performance. 168 different models were implemented for testing all possible policy alternatives. We have found feasible solutions for all of these models. In 116 of these models, we did not see significant backlog. Presented model and results were debated with the management team of this production site and findings obtained from this study were found realistic by them consistent with the planning data. Objective function of model was verified by the outcomes in other words.

Table 9. Scenarios considered in this work

\begin{tabular}{cl}
\hline Main Criteria & \multicolumn{1}{c}{ Categories } \\
\hline Demand Data & $\begin{array}{l}\text { Forecasted Data } \\
\text { Safety Stock Decision-0 (No Safety Stock) }\end{array}$ \\
\cline { 2 - 2 } Safety Stock Decision-1: 90\% Service Level for All Grades \\
\cline { 2 - 2 } Inventory Policy & Safety Stock Decision-2: 95\% Service Level for All Grades \\
& Safety Stock Decision-3: Different Service Level Rates for All Grades \\
\hline Capacity Policy & $\begin{array}{c}\text { Production Throughput: Low (655 t/d) to High (725 t/d) } \\
\text { Energy Resource: Only Natural Gas }\end{array}$ \\
\cline { 2 - 2 } Energy Policy & Energy Resource: Both (Natural Gas and Coal) by 50\% usage \\
\cline { 2 - 2 } & Energy Resource: Only Coal \\
\hline
\end{tabular}

Source: The authors themselves.

Since total profit is our objective function, it is desired to be high as much as possible. On the other hand, we try to keep the total cost, total product inventory and generated carbon emission amount at the minimum level. We also want to keep the production size and utilization rate at optimum levels.

\section{Forecasting demand and accuracy}

Forecasting accuracy is crucial for production planning. Although the estimation may not exactly accurate, it is highly for required for planning. Time series forecasting use historical data as the basis of estimating future outcomes. Holt-Winter (HW) and ARIMA methods are used in this study since the test data showed that they produce higher accuracy when compared to other forecasting methods (traditional methods like moving average method, regression analysis etc.).

We have used Root Mean Squared Error (RMSE), Mean Absolute Error (MAE) and Mean Absolute Percentage Error (MAPE) as the error metrics of two forecast methods. The performance of two forecasting methods is as given in Table 10 for all product types (grades). Since smaller error values are preferable, we see that ARIMA method produces the less error for all product types. 
Table 10. Comparison of different forecasting errors by product grade and forecasting method

\begin{tabular}{|c|c|c|c|c|c|c|}
\hline \multirow{2}{*}{ Forecast Method } & \multirow{2}{*}{$\begin{array}{c}\text { Forecast Error } \\
\text { Metric }\end{array}$} & \multicolumn{4}{|c|}{ Product Grade } & \multirow{2}{*}{ Average } \\
\hline & & 0.76 IV & $0.80 \mathrm{IV}$ & 0.84 IV & All & \\
\hline \multirow{3}{*}{ ARIMA } & RMSE & 1.27 & 0.92 & 1.18 & 0.93 & 1.08 \\
\hline & MAE & 0.94 & 0.85 & 0.95 & 0.71 & 0.86 \\
\hline & MAPE & 0.09 & 0.28 & 0.18 & 0.04 & 0.15 \\
\hline \multirow{3}{*}{ HW } & RMSE & 1.34 & 2.90 & 1.79 & 1.57 & 1.90 \\
\hline & MAE & 1.21 & 2.59 & 1.59 & 1.26 & 1.66 \\
\hline & MAPE & 0.12 & 0.92 & 0.29 & 0.06 & 0.35 \\
\hline
\end{tabular}

Source: The authors themselves.

\section{RESULTS}

Model results and the actual situation in the plant (real results belong to 2017 year) are compared and it is seen that significant improvements can be achieved. Increase in any variable is shown by $+\%$ and decrease in any variable is shown by $-\%$. You can see the findings in Table 11 and Table 12. The results given in table 11 are the average values of the two best models obtained from selected energy resource. Model results contains objective function, total cost, production and inventory quantities, different cost shares and other performance variables (utilization rate and inventory turnover rate) values. We have seen that the best results can be obtained if the $3^{\text {rd }}$ alternative for safety stock is chosen and only natural gas or both natural gas and coal are used as energy resource. Actual situation in the plant can be seen in Table 12 .

Table 11. Best results (improvement rate by percentages) with forecasted demand data

\begin{tabular}{lcc}
\hline \multicolumn{1}{c}{ Performance Variables } & \multicolumn{2}{c}{ Energy Resource } \\
& Natural Gas & Natural Gas + Coal \\
\hline Production Capacity / t/d & 725 & 725 \\
\hline Objective Function: Total Profit / \% & 6.6 & 5.4 \\
\hline Total Cost / \% & -6.9 & -6.6 \\
\hline Revenue / \% & -3.9 & -3.9 \\
\hline Total Production Quantity / \% & -3.9 & -3.9 \\
\hline Total Net Inventory Quantity / \% & -28.3 & -28.5 \\
\hline Total Average Inventory Quantity / \% & -28.2 & -28.4 \\
\hline Total Safety Stock Overstock Quantity / \% & -649.4 & -663.9 \\
\hline Total Number of Setups / \% & -136.1 & -136.1 \\
\hline Utilization Rate Average Value / \% & -14.1 & -14.1 \\
\hline Safety Stock Overstock cost / \% & -19.0 & -21.3 \\
\hline Setup Cost / \% & -136.1 & -136.1 \\
\hline Production Cost / \% & -3.9 & -3.9 \\
Total Raw Material Cost / \% & -3.6 & -3.6 \\
Total Additive Material Cost / \% & -8.3 & -8.3 \\
Energy Cost / \% & -245.4 & -161.8 \\
\hline Total Utility Cost / \% & -103.0 & -89.3 \\
\hline Total Generated Emission / \% & -245.2 & -161.9 \\
Annual Inventory Turnover Ratio for all Production / \% & 19.1 & 19.3 \\
Annual Inventory Holding Time for all Production / \% & -23.6 & -23.9 \\
\hline Source The auths & & \\
\hline
\end{tabular}

Source: The authors themselves. 
Table 12. Comparison of real data and best optimal results

\begin{tabular}{|c|c|c|c|}
\hline DEMAND DATA & REAL VALUES & $\begin{array}{l}\text { FORECASTED VALUES: } \\
\text { ARIMA }\end{array}$ & $\begin{array}{c}\text { FORECASTED VALUES: } \\
\text { ARIMA }\end{array}$ \\
\hline ENERGY SOURCE & NATURAL GAS + COAL* & NATURAL GAS & NATURAL GAS + COAL \\
\hline INVENTORY POLICY & $\begin{array}{c}\text { WITHOUT BACKLOG } \\
\text { AND SS* }\end{array}$ & $\begin{array}{c}\text { WITH BACKLOG AND } \\
\text { SS }\end{array}$ & $\begin{array}{c}\text { WITH BACKLOG AND } \\
\text { SS }\end{array}$ \\
\hline SAFETY STOCK DECISION & SS-0 & SS-3 & SS-3 \\
\hline PRODUCTION CAPACITY POLICY / t/d & CHANGEABLE* & 725 & 725 \\
\hline OBJECTIVE FUNCTION / Total Profit / M \$ & 75.6 & 80.9 & 79.9 \\
\hline Total Cost / M \$ & 298.2 & 278.8 & 279.8 \\
\hline Revenue / M \$ & 373.8 & 359.8 & 359.7 \\
\hline Total production quantity $/ 10^{3} \mathrm{t}$ & 249.2 & 239.8 & 239.8 \\
\hline Total net inventory quantity $/ 10^{3} \mathrm{t}$ & 24.8 & 19.34 & 19.30 \\
\hline Total average net inventory quantity $/ 10^{3} \mathrm{t}$ & 2.1 & 1.6 & 1.6 \\
\hline Total average inventory quantity of grade $\mathrm{j}_{1} / 10^{3} \mathrm{t}$ & 1.2 & 1.0 & 1.0 \\
\hline Total average inventory quantity of grade $\mathrm{j}_{2} / 10^{3} \mathrm{t}$ & 0.3 & 0.3 & 0.3 \\
\hline Total average inventory quantity of grade $\mathrm{j}_{3} / 10^{3} \mathrm{t}$ & 0.6 & 0.4 & 0.4 \\
\hline Total safety stock overstock quantity $/ 10^{3} \mathrm{t}$ & 13.0 & 1.7 & 1.7 \\
\hline Total safety stock shortage quantity $/ 10^{3} \mathrm{t}$ & 0.0 & 1.6 & 1.6 \\
\hline Total backlog quantity $/ 10^{3} \mathrm{t}$ & 0.0 & 0.0 & 0.0 \\
\hline Total number of setups & 85 & 36 & 36 \\
\hline Utilization rate average value / \% & 103.4 & 90.6 & 90.6 \\
\hline Service level average value / \% & 100.0 & 100.0 & 100.0 \\
\hline Safety stock overstock cost / M \$ & 0.62 & 0.52 & 0.51 \\
\hline Safety stock shortage cost / M \$ & 0.00 & 4.80 & 4.80 \\
\hline Backlog cost / M \$ & 0.00 & 0.00 & 0.00 \\
\hline Setup cost / M \$ & 0.01 & 0.00 & 0.00 \\
\hline Production cost / M \$ & 1.25 & 1.20 & 1.20 \\
\hline Total raw material cost / M \$ & 258.7 & 249.7 & 249.7 \\
\hline Total additive cost / M \$ & 9.35 & 8.64 & 8.64 \\
\hline Utility-2 (Energy) cost / M \$ & 10.9 & 3.2 & 4.2 \\
\hline Total utility cost / M \$ & 28.3 & 13.9 & 14.9 \\
\hline Total generated carbon emission / $\mathrm{t}$ & 0.06 & 0.02 & 0.02 \\
\hline Total demand $/ 10^{3} \mathrm{t}$ & 237.4 & 236.5 & 236.5 \\
\hline Annual inventory turnover ratio for all production & 118.7 & 146.8 & 147.0 \\
\hline Annual inventory turnover ratio for production of grade $j_{1}$ & 108.6 & 131.8 & 132.2 \\
\hline Annual inventory turnover ratio for production of grade $\mathrm{j}_{2}$ & 150.1 & 137.1 & 137.1 \\
\hline Annual inventory turnover ratio for production of grade $\mathrm{j}_{3}$ & 124.8 & 193.6 & 193.6 \\
\hline Annual inventory holding time for all production / day & 3.1 & 2.5 & 2.5 \\
\hline Annual inventory holding time for production of grade $\mathrm{j}_{1} /$ day & 3.4 & 2.8 & 2.8 \\
\hline Annual inventory holding time for production of grade $\mathrm{j}_{2}$ / day & 2.4 & 2.7 & 2.7 \\
\hline Annual inventory holding time for production of grade $\mathrm{j}_{3} /$ day & 2.9 & 1.9 & 1.9 \\
\hline
\end{tabular}

Source: The authors themselves.

Performance variables shown with the sign with * in Table 12, means that these are not exactly as described in proposed model. Energy source is 'Natural Gas + Coal' but these sources were not used equally. There was not backlog issue according to provided information. Capacity policy was also determined to produce maximum throughput generally, but it was not a regular process.

Before comparing the model alternatives, we have to mention about the model names. The model name " $\mathrm{FOR}+\mathrm{BOTH}+\mathrm{SS}_{3}$ " represents the model using both energy resources at the same time and using $\mathrm{SS}_{3}$ alternative for inventory policy. Model name as "FOR + NG + $\mathrm{SS}_{3}$ " represents the model using only natural gas for energy and using $\mathrm{SS}_{3}$ alternative for inventory policy.

We can summarize the obtained improvements for different scenarios as follows: 
1. Improvement in the objective function value (total profit), total cost and revenue can be seen in Figure 1. The improvement in the total profit and the total cost inversely proportional to each other. However, decrease in the total cost does not decrease much if capacity is changed from 655 tons/day to 675 tons/day. Profit improvement increases after a change in 655 tons/day capacity to 675 tons/day capacity. Rate of increase is almost constant after $670 \mathrm{t} / \mathrm{d}$ capacity. Improvement rate of revenue and total cost are negative. Thus it is possible to make profit by increasing the capacity. Improvement in revenue is negative since only necessary amount of production is allowed.

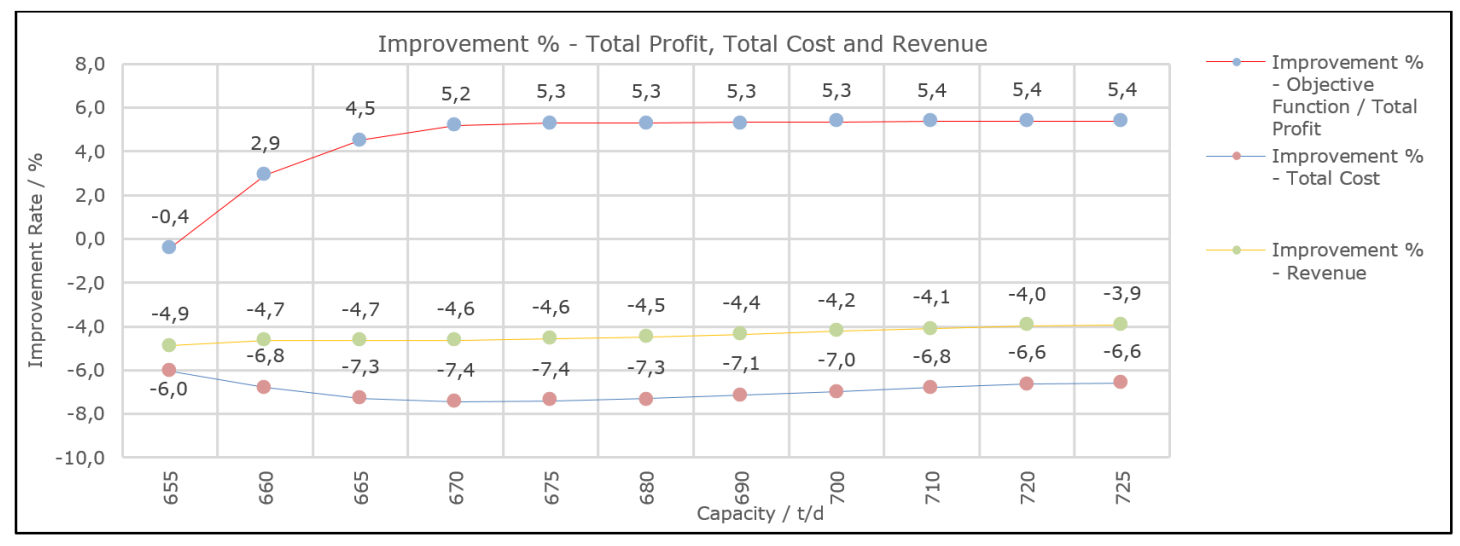

Figure 1. Improvement \% / Total Profit, Total Cost and Revenue Source: The authors themselves.

2. Comparison of improvements in objective function (total profit), total cost and revenue value for the models considering the natural gas and both resources as the energy resource is presented in Figure 2. It is obvious that use of natural gas as an energy resource is more advantageous in terms of cost and profit.

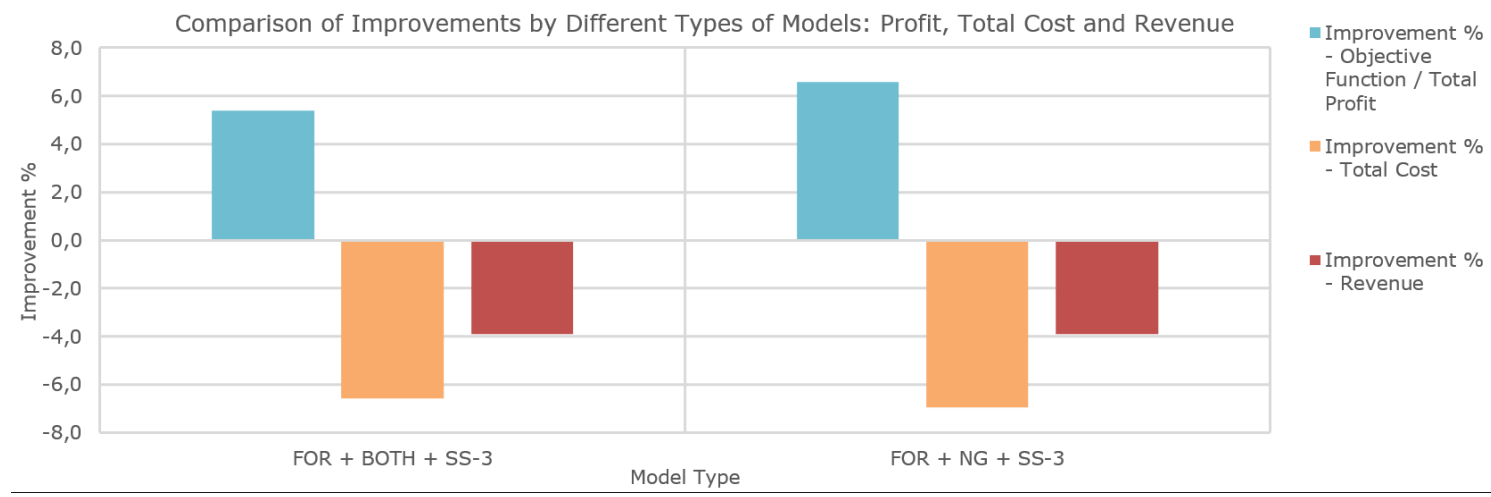

Figure 2. Comparison of Improvements by Different Types of Models: Profit, Total Cost and Revenue Source: The authors themselves.

3. Improvement in the total production amount and total average inventory amount can be seen in Figure 3. Best improvement for average inventory is found for 675 tons/day capacity. 


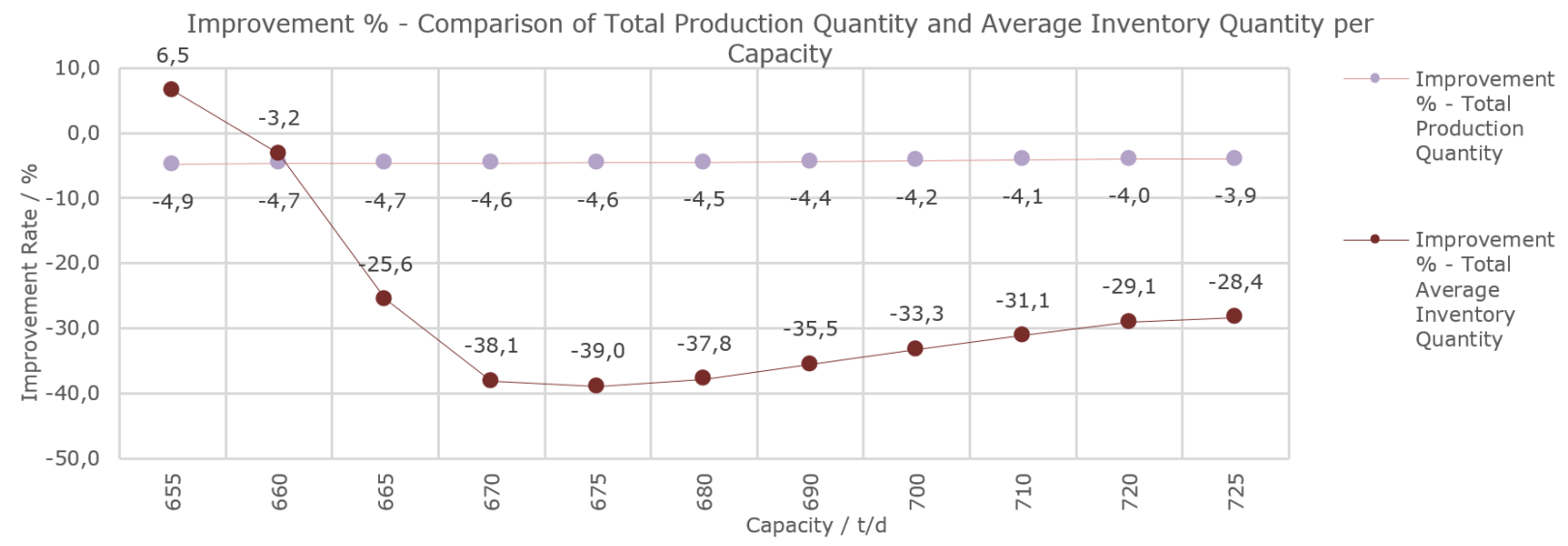

Figure 3. Improvement\% versus Comparison of Total Production Quantity and Average Inventory Quantity per Capacity

Source: The authors themselves.

4. Comparison of improvements for total production quantity, total inventory quantity and total overstock quantity is as shown in Figure 4. Decrease of production quantity, inventory quantity and overstock quantity is almost same on both of models.

Comparison of Improvements by Different Types of Models: Total Production Quantity, Total Inventory Quantity and Total Overstock Quantity

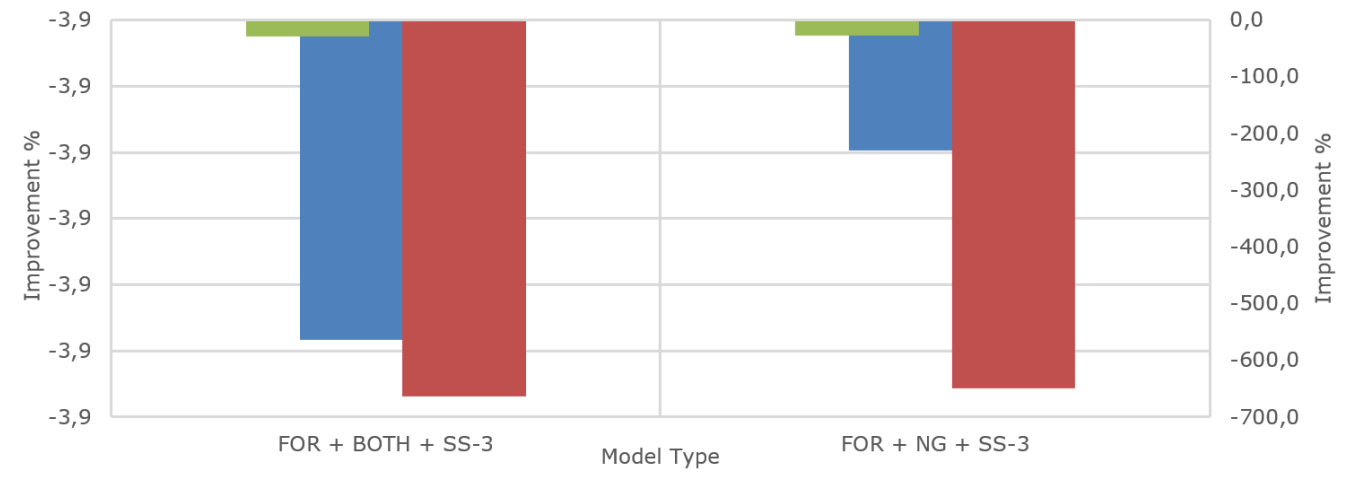

Figure 4. Comparison of Improvements by Different Types of Models: Total Production Quantity, Total Inventory Quantity and Total Overstock Quantity

Source: The authors themselves.

5. Capacity is chosen as much as possible $(725 \mathrm{t} / \mathrm{d})$ in order to reduce the utilization rate. Utilization rate is calculated as $103.4 \%$ due to low value of maximum capacity (660 t/d) and higher production quantity is expected than assumed maximum production according to the real results of 2017 year. Utilization rate is one of the key performance variables of production: production efficiency increases proportionally with it. However utilization rate must be lower than $100 \%$ to keep better production conditions and handle immediate demands properly. Efficient capacity utilization is one of the expected results of optimal production plan. Total production volume reduction rate is $3.9 \%$. Utilization reduction rate is $14.1 \%$. Total number of setups reduction rate is $136.1 \%$ for both models.

6. Improvement percentage of utilization rate is seen on Figure 5. Utilization rate decreases by increasing capacity. 


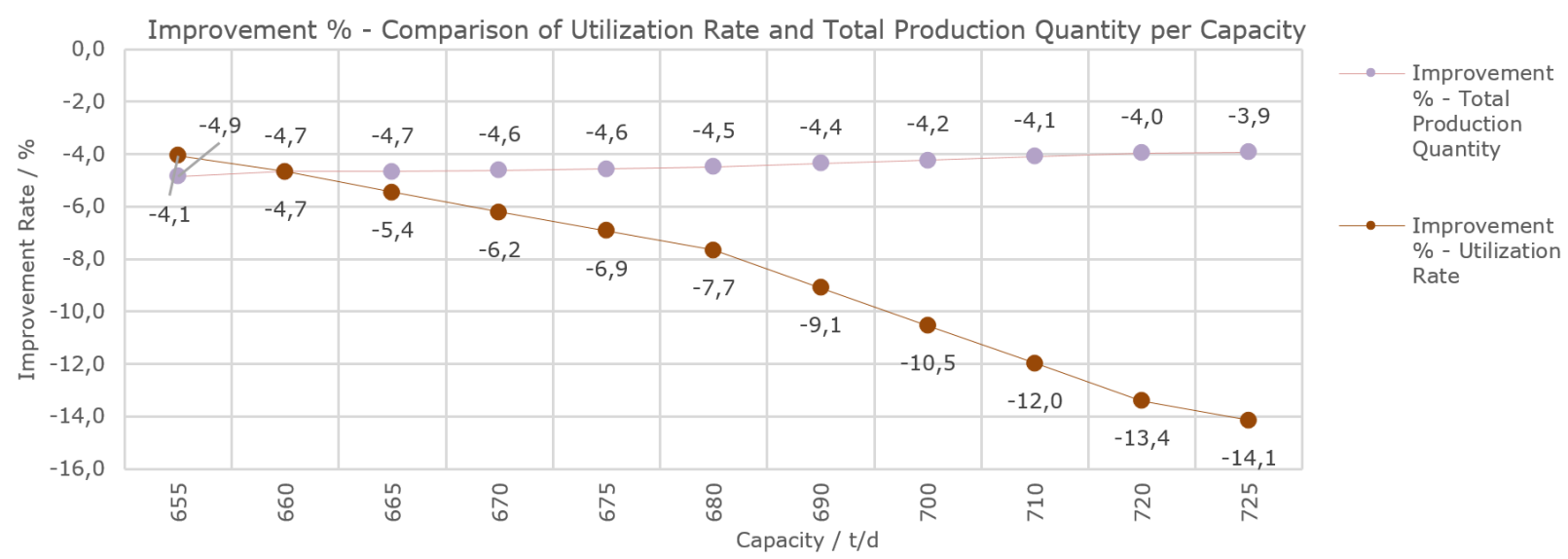

Figure 5. Improvement \% / Comparison of Utilization Rate and Total Production Quantity per Capacity Source: The authors themselves.

7. Comparison of improvement rates of total production size, total number of setups and utilization rate is seen on Figure 6 . Change of production amount and utilization rate could be seen from primary axis and change of number of setups could be seen from secondary axis. Total number of setups has dropped to a great extent with the help of optimal plan for all models. Improvement rates of both models are almost the same.

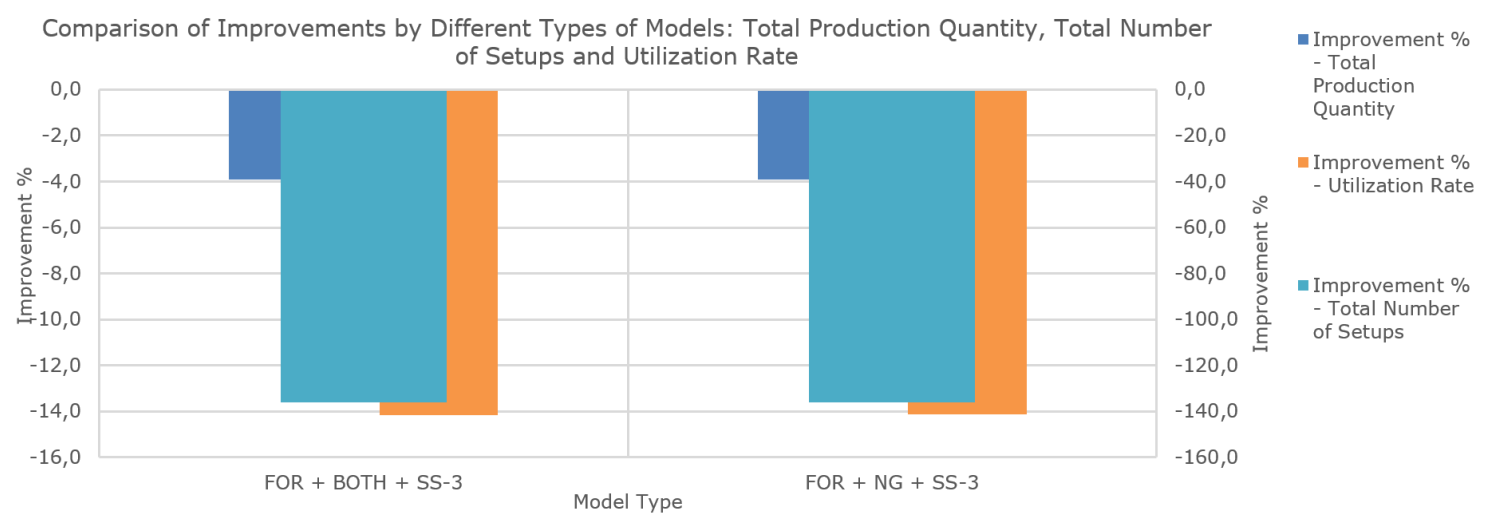

Figure 6. Comparison of Improvements by Different Types of Models: Total Production Quantity, Total Number of Setups and Utilization Rate Source: The authors themselves.

8. Production cost reduction rate is $3.9 \%$. Setup cost reduction rate is $136.1 \%$ for both models. Total raw material cost reduction rate is $3.6 \%$. Total additive material cost reduction rate is $8.3 \%$. Total utility resource cost reduction rate is $96.2 \%$. It can be said that the implementation of the model is beneficial in terms of cost reduction especially for setup cost and utility cost. Findings can be seen on Figure 7, 8, 9 and 10.

9. Improvement percentages of total cost, production cost, raw material cost and additive material cost is shown in Figure 7. 


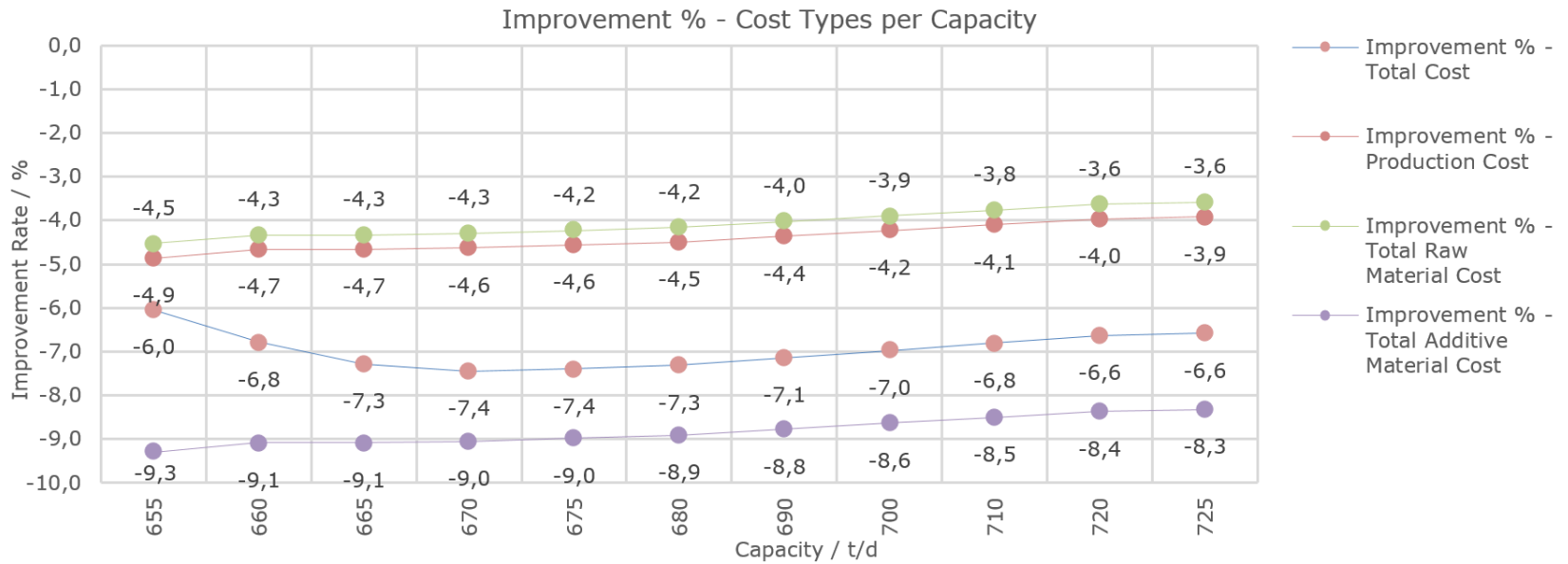

Figure 7. Improvement \% versus Cost Types per Capacity-1 Source: The authors themselves.

10. Comparison of improvement rates of various cost types is seen on Figure 8 and Figure 10. The most remarkable achievements are seen on setup cost and total utility cost. Improvement rate obtained from results on production and material costs (raw and additive) is more modest than utility cost and setup cost.

Comparison of Improvements by Different Types of Models: Production Cost, Raw Material Cost and

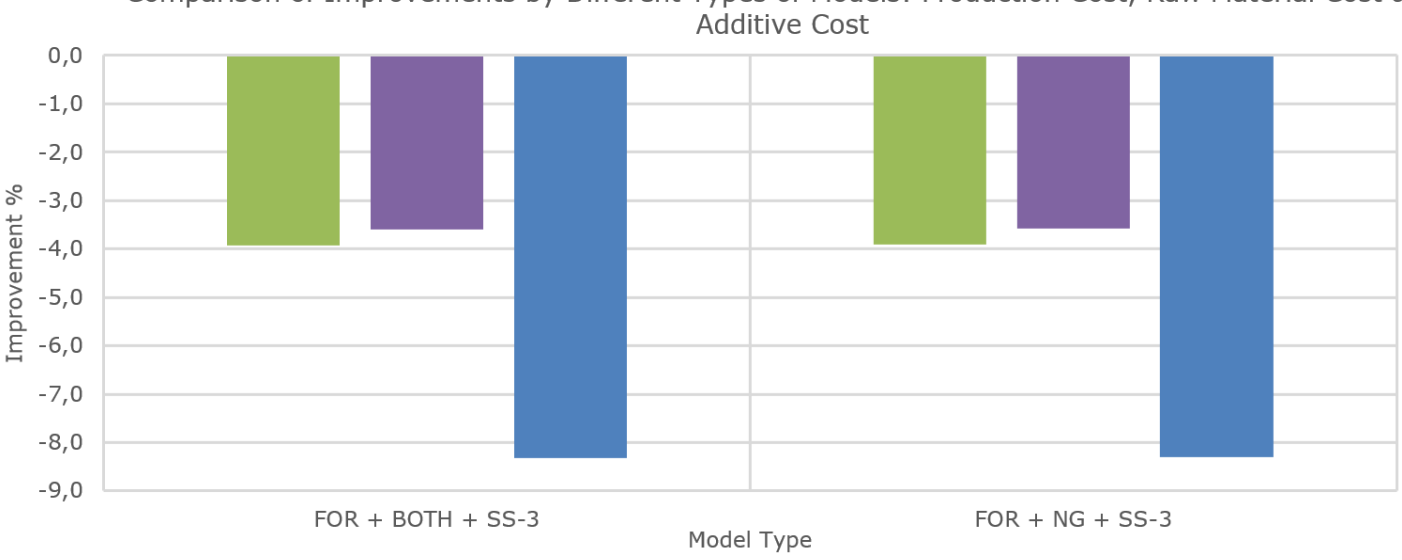

Improvement \% Production Cost

Improvement \% Total Raw Materia Cost

Figure 8. Comparison of Improvements by Different Types of Models: Production Cost, Raw Material Cost and Additive Cost Source: The authors themselves.

11. Improvements in total utility cost, energy cost and energy consumption is as shown in Figure 9. High level of improvement for all cost types is achieved. 


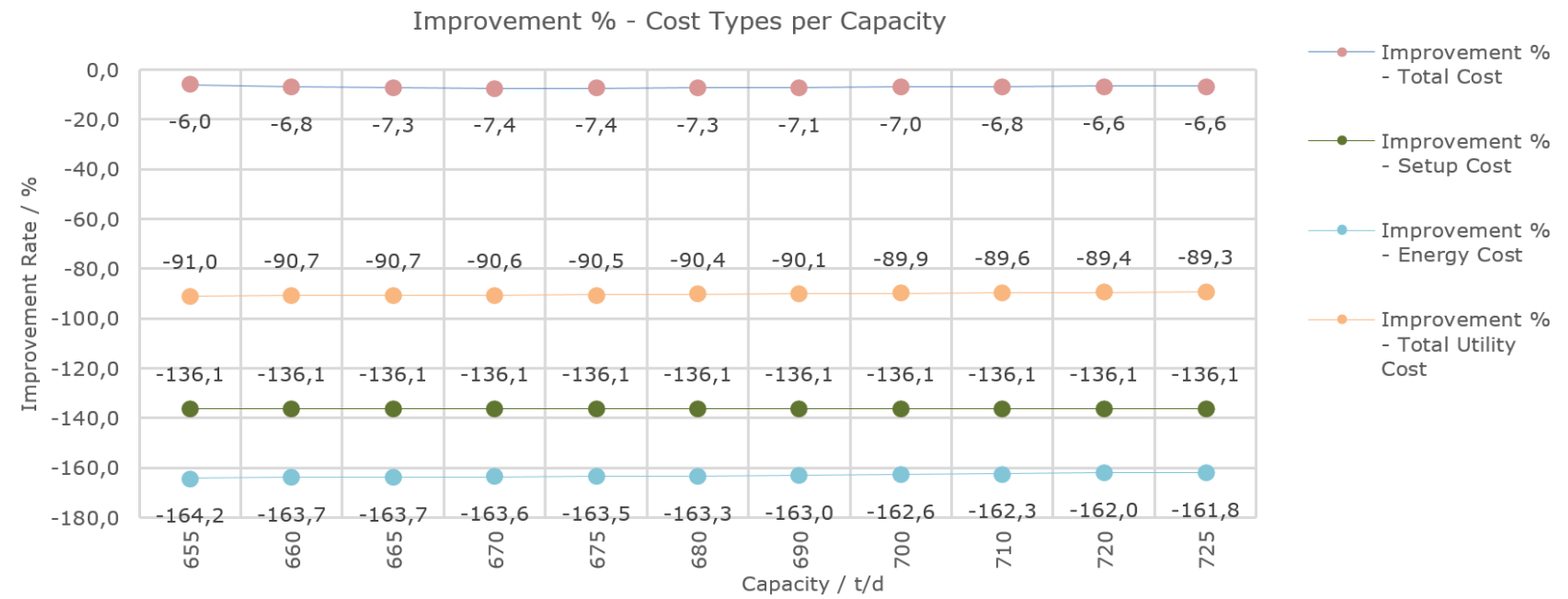

Figure 9. Improvement versus Cost Types per Capacity-2 Source: The authors themselves.

12. Comparison of improvements in setup cost, total utility cost and energy cost is depicted in Figure 10. Total utility cost decreases dramatically, but the cost of energy included in the cost of utility falls considerably. Reduction rate of energy cost is higher than total utility cost. Reduction rate of total utility cost and energy cost is higher on model using natural gas as energy resource than model using both energy sources as energy resource.

Comparison of Improvements by Different Types of Models: Total Utility Cost and Energy Cost

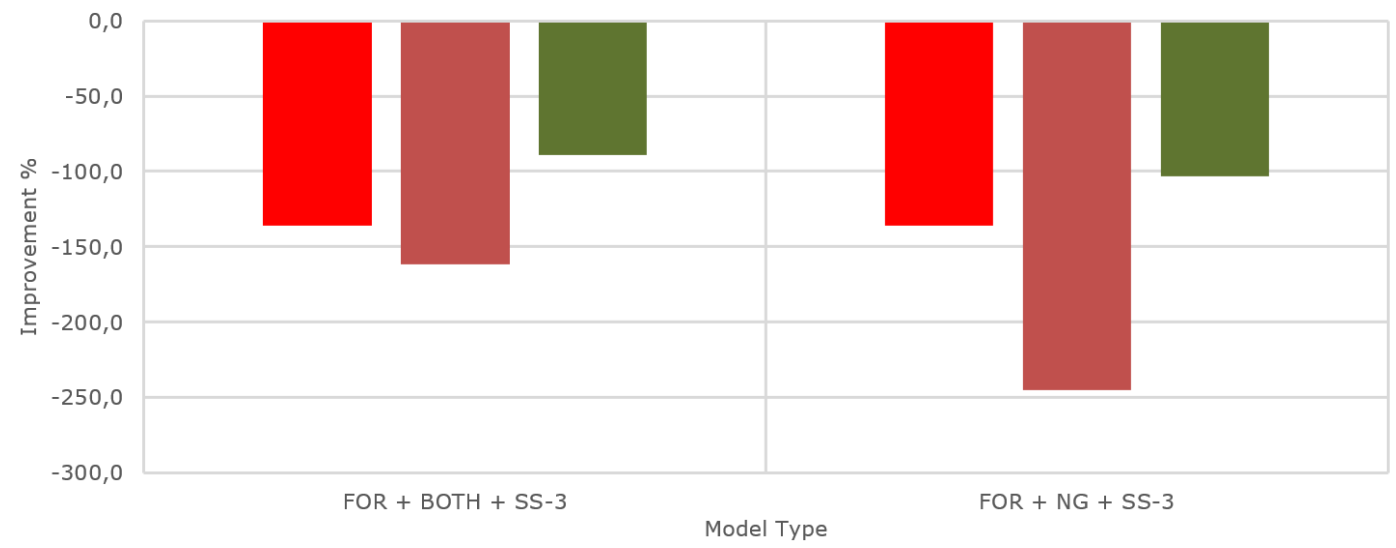

- Improvement \% Setup Cost

- Improvement \% Energy Cost

Figure 10. Comparison of improvements for different scenarios (Total Utility Cost, Energy Cost and Setup Cost)

Source: The authors themselves.

13. Relation between generated carbon emission and production size can be seen in Figure 11. Improvement in generated carbon emission is similar to improvement rate in production quantity. 


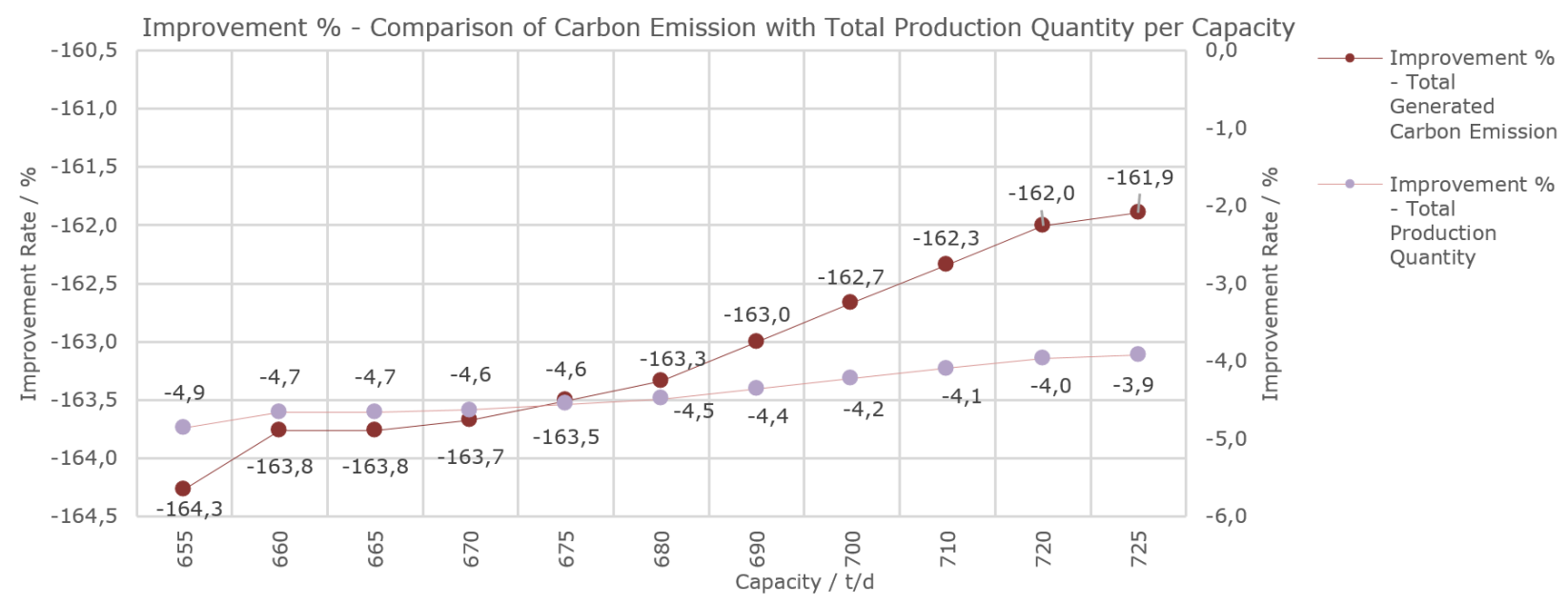

Figure 11. Improvement \% / Comparison of Carbon Emission with Total Production Quantity per Capacity

Source: The authors themselves.

14. Comparison of improvement in energy cost, energy consumption and total generated carbon emission is as depicted in Figure 12. Decrease of energy cost, energy consumption and total generated carbon emission are almost the same on both models and reduction rates are higher on model using natural gas as energy resource. The results are striking, decrease of energy cost, energy consumption and total generated carbon emission is very high even on model using both energy sources as energy resource.

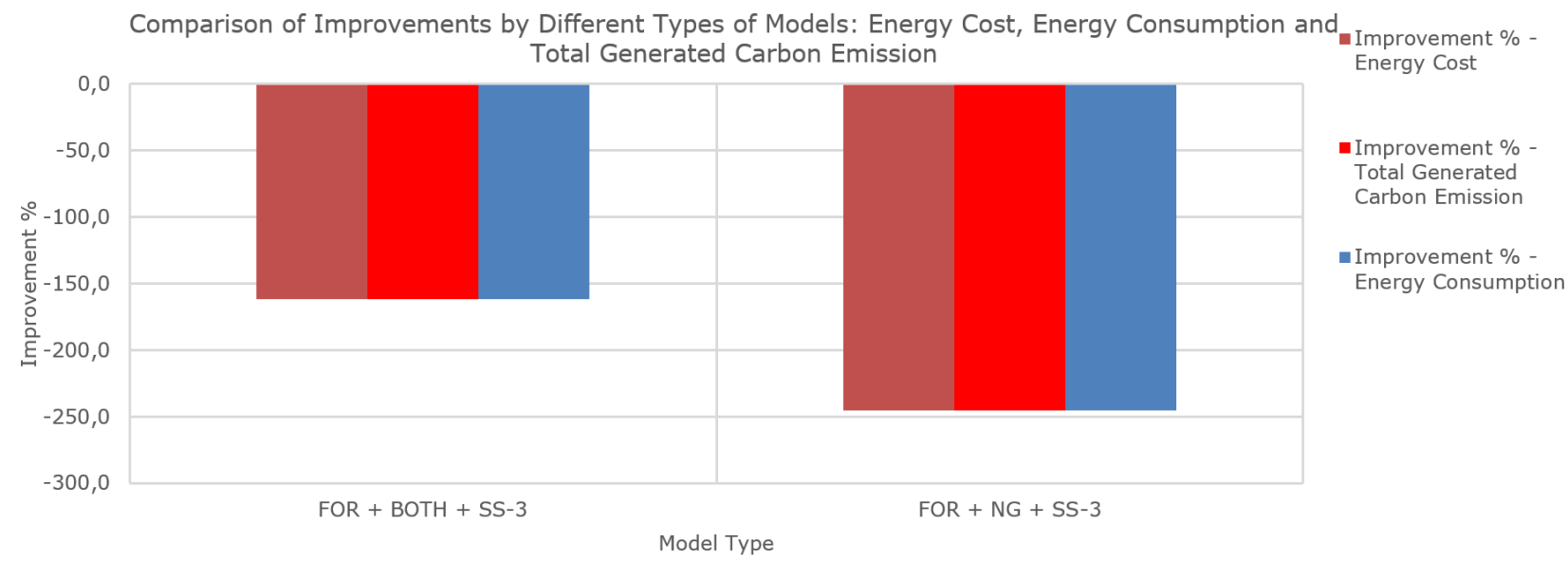

Figure 12. Comparison of improvements by Different Types of Models: Energy Cost, Energy Consumption and Total Generated Carbon Emission Source: The authors themselves.

15. Improvement in inventory turnover ratio of total production amount increases after production capacity reaches $655 \mathrm{t} / \mathrm{d}$ capacity and decreases after production capacity reaches $675 \mathrm{t} / \mathrm{d}$ as it can be seen in Figure 13. Improvement of inventory turnover ratio of product grade $j_{2}$ and $j_{3}$ reach their peak values when capacity reaches to a definite point (660 tons/day for product grade $j_{2}$ and 670 tons/day for product grade $j_{3}$ ) and become constant during regular capacity increase. 


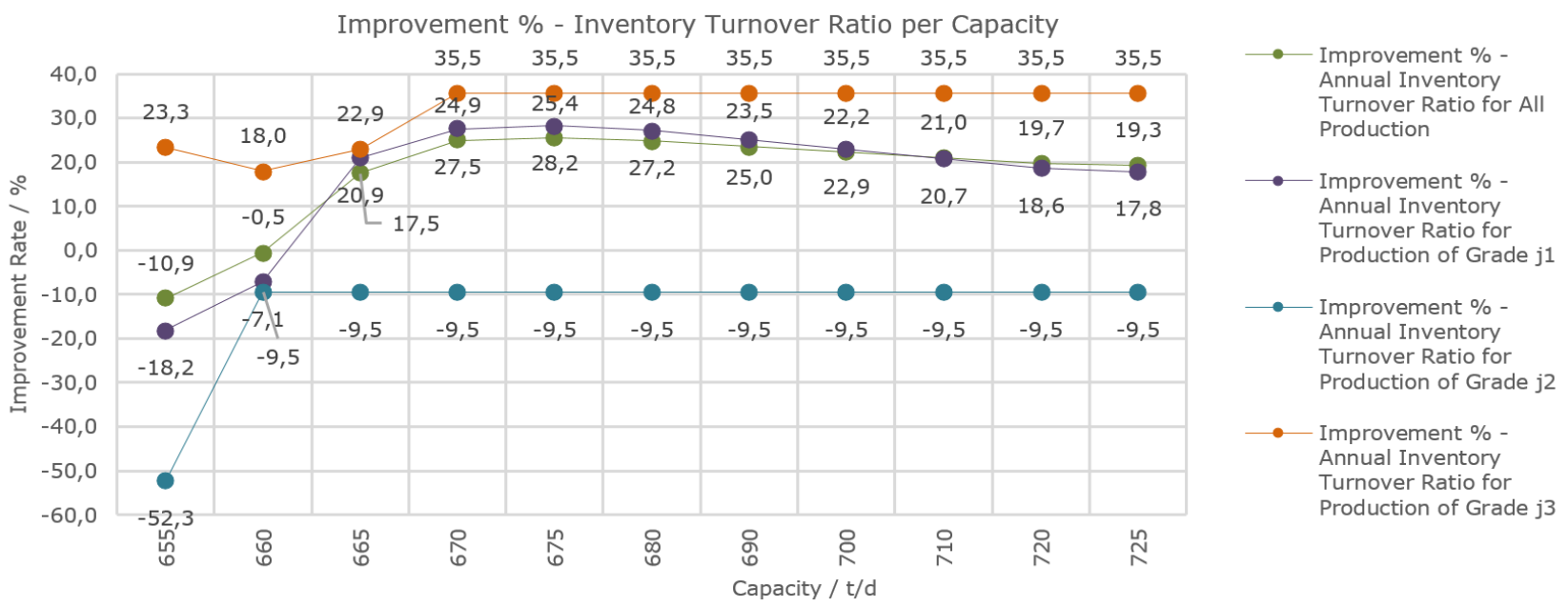

Figure 13. Improvement \% / Inventory Turnover Ratio per Capacity Source: The authors themselves.

16. Comparison of improvement in the inventory turnover ratio for total production and for product grades is shown in Figure 14. Improvement in inventory turnover ratio of all product grades significantly increases except of product grade $j_{2}$. Results obtained from both models are the same. This also shows that there is no direct relationship between energy resource and inventory holding time when the same demand data is used.
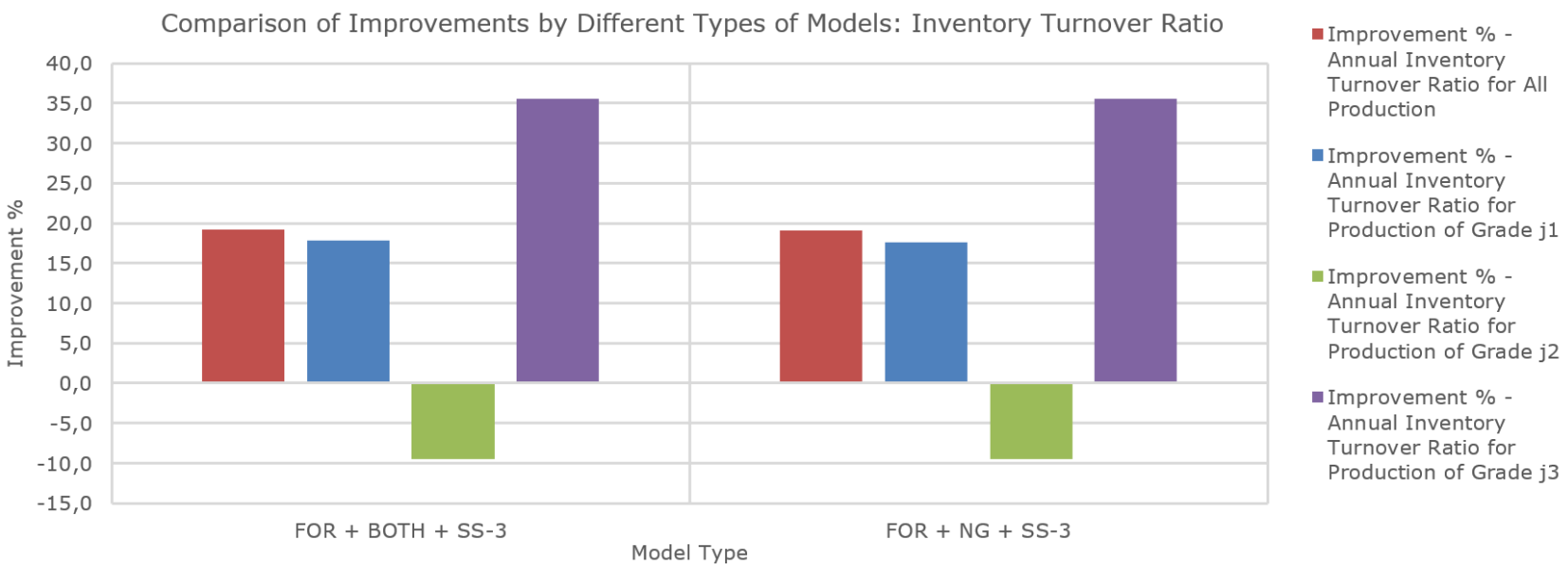

Figure 14. Comparison of Improvements by Different Types of Models: Inventory Turnover Ratio Source: The authors themselves.

17. Improvement rate trend of inventory holding time is seen on Figure 15. Inventory turnover ratio and inventory holding time is inversely proportional between each other. When inventory turnover ratio is high, inventory holding time is low meantime. Improvement rate trend of inventory holding time is almost opposite of the trend seen in Figure 16.

18. There is a peak value on inventory holding time trend on different capacity values for all production grades (655 tons/day for $\mathrm{j}_{1}, \mathrm{j}_{2}$ and total production and 660 tons/day for $\mathrm{j}_{3}$ ). Improvement in inventory holding time of product grade $\mathrm{j}_{2}$ and $\mathrm{j}_{3}$ reach their minimum values when production capacity reaches to a definite point (660 tons/day for product grade $j_{2}$ and 670 tons/day for product grade $j_{3}$ ) and become constant during regular capacity increase. 


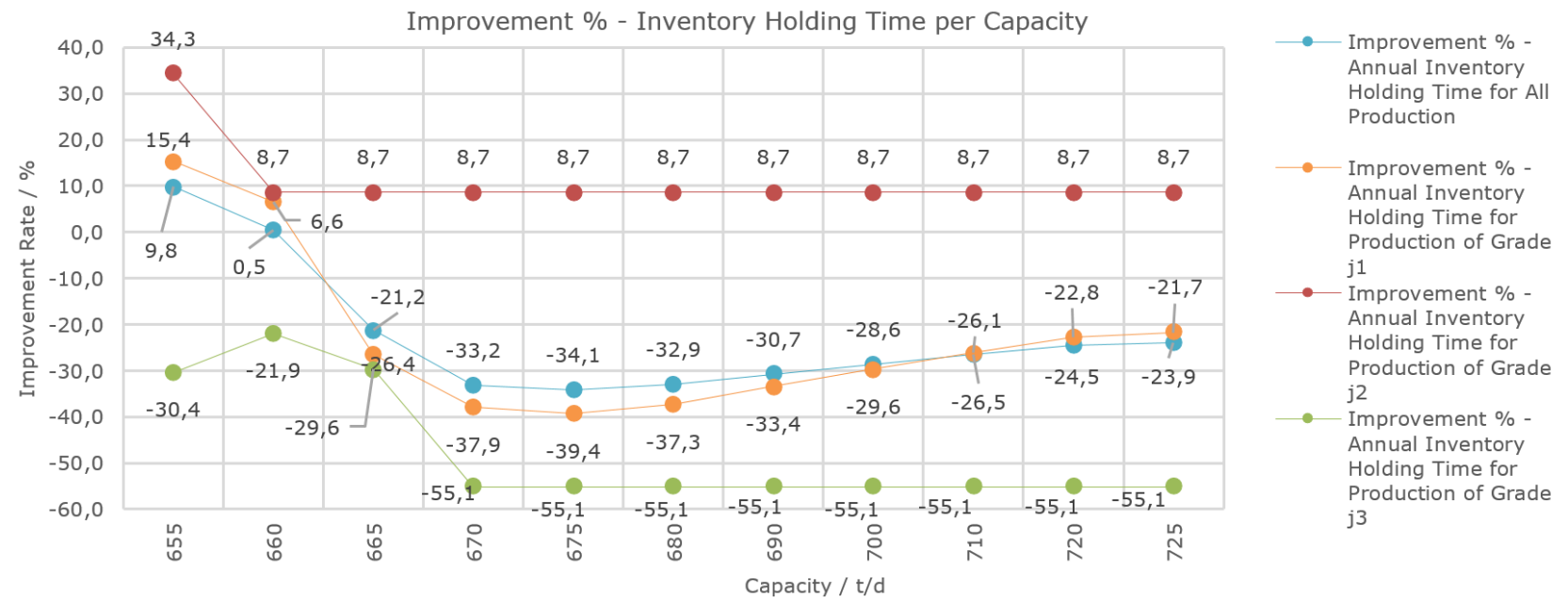

Figure 15. Improvement \% / Inventory Holding Time per Capacity Source: The authors themselves.

19. Comparison of improvements in inventory holding time for total production and for product grades separately shown in Figure 16. Improvement in inventory holding time of product grades significantly decreased except "product grade $\mathrm{j}_{2}$ ". Results obtained from both models are the same. This also shows that there is no direct relationship between energy resource and inventory holding time when the same demand data is used.

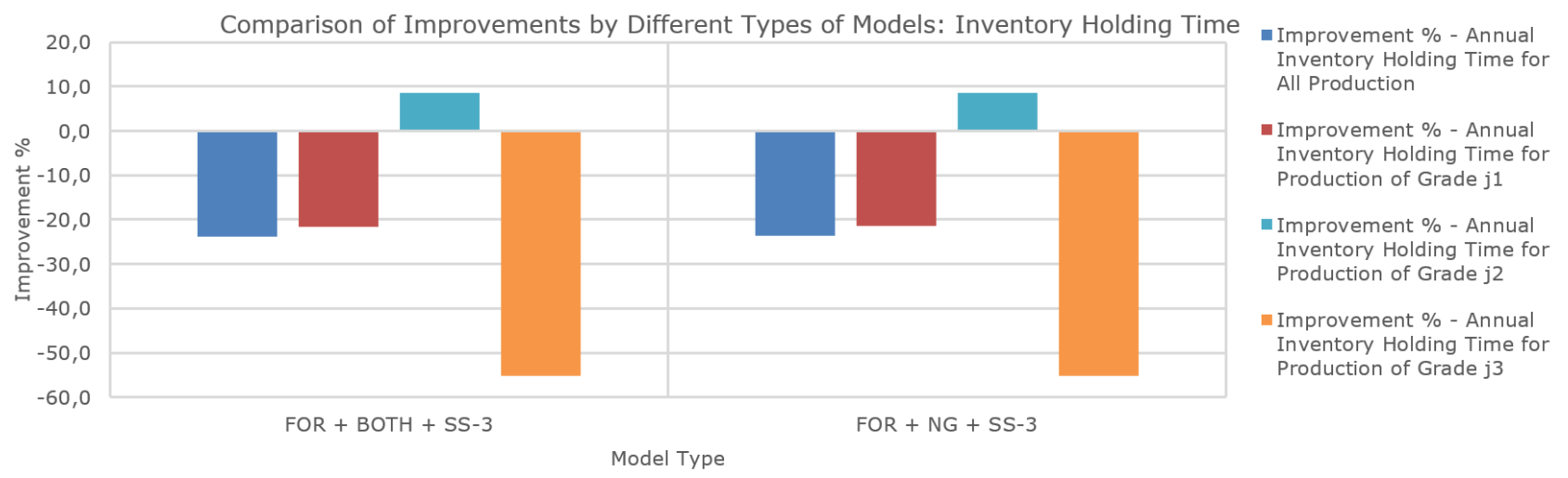

Figure 16. Comparison of improvements by different types of models: Inventory Holding Time Source: The authors themselves.

\section{Evaluation of results and discussion}

Applications of lot sizing are carried out in various industrial areas. Different benefits are obtained from results according to related problem or target. Benefits obtained are briefly reviewed according to their specific categories on (Díaz-Madroñero et al., 2014) and most of realworld applications which were published in INFORMS are listed on (Chen et al., 2011). There are some studies which include more developed structure to reach more than one target in literature. A work leans on aggregated production planning considering cultural environment (Kazan, 2018), another work which contains integrated planning model aims to schedule production and work shifts detailed (Teksan, 2011) and a dissertation on production planning model of an ice cream factory (Bude, 2008) are among these studies. Results can be evaluated between these works, because even if models of these problems are different for most points, they are in the same class of production planning problems and they have many similarities.

Improvements obtained from this study could be summarized as below: 
1. The objective of model is to maximize profit. Profit has increased by $6.0 \%$ and total cost has reduced by $6.8 \%$ according to results obtained. Profit is equivalent to $5.4 \mathrm{M} \$$ and cost reduction is equivalent to almost $20.0 \mathrm{M} \$$. According to list of published real-world applications, this value is not lower than these savings (Chen et al., 2011).

2. Direct and indirect effects of suggested plan are seen obviously on obtained results. Energy consumption, generated carbon emission amount and energy cost decreases significantly and it is the direct effect of plan. Total production quantity reduced consequently excess production is minimized and these are the indirect effects of the plan. The importance of the energy source is vital to carry out that kind of production plan, too. There are three alternatives for energy source. Best option is natural gas owing to least emission generation and cheapest price in terms of use of energy source. Coal is the worst alternative for both economic and environmental views. Energy consumption, energy cost and generated carbon emission amount reduction rate is 203.6\%. Different cost shares and environmental impact are also examined on (Kazan, 2018). Objective of one of the recent studies is evaluate the potential of strategies to promote green corridors (reduce $\mathrm{CO}_{2}$ emission) of soybean exports (Péra et al., 2019).

3. Operation with high capacity is more advantageous than low capacity. Because demand fluctuations can be handled better and inventory storage is reduced with that strategy. Additionally utilization rate could be decreased to have a margin for controlling immediate production orders. Capacity is chosen as much as possible $(725 \mathrm{t} / \mathrm{d})$ in order to reduce utilization rate. Efficient capacity utilization is one of the expected results of optimum production plan. Total production volume reduction rate is $3.9 \%$. Utilization reduction rate is $14.1 \%$. It reduces from $103.4 \%$ to $90.6 \%$. Reduction rate of total number of setups is $136.1 \%$ for all models. Utilization is one of the less studied topics for lot sizing. (Erenay et al., 2015) contributes one of these works and goal of this article is modeling a stochastic capacitated lot sizing by trials between capacity and utilization.

4. There is a tradeoff between expected service level by safety stocks and inventory holding cost. Most favorable inventory policy is modeled to balance production principles and market requirements. Third alternative for safety stock is chosen for inventory policy because expected consumer service level is obtained with more flexible way. As said by the results obtained, even if there is particular amount of stock in every period, inventory turnover ratio increased and inventory holding time reduced. Inventory policy used for production plan is successful except of product grade $\mathrm{j}_{2}$. Annual inventory turnover ratio increment rate is $19.2 \%$ and annual inventory holding time reduction rate is $23.7 \%$. Total net inventory quantity reduction rate is $28.4 \%$ and inventory overstock quantity reduction rate is $656.6 \%$.

\section{CONCLUSIONS}

This work could be defined as an implementation of a basic production planning model to one of the bottle grade PET manufacturers in Turkey deeming sustainability. Sustainable manufacturing is the creation of manufactured products through economically-sound processes that minimize negative environmental impacts while conserving energy and natural resources according to definition given on (United States Environmental Protection Agency, 2017). Results obtained from model prove that optimal production plan is useful for not only economic objectives but also environmental approaches. It could be possible when production plan is integrated with sustainability. Even that kind of integration is on basic level in our model, visible improvements obtained from the proposed model.

Also methodology used in this work can be useful for similar type of works, because comparative analysis of implemented models could reveal which model is more functional for different scenarios and with the help of this much more efficient aggregated large-scale production plans could be projected. In addition to this, studies have been carried out on the forecasting which has great importance in planning. Proper forecasting method is chosen and consequently much reliable results are obtained. Those outcomes show that this work can be 
implemented notably at another PET resin plants as well as other factories using similar production processes with help of the suggested model. On the other hand simulation could be preferred rather than mathematical modeling on future works in order to see which method is more useful. There is limited research about this area, so it could be helpful for other real-world applications especially on PET resin production plants.

\section{REFERENCES}

Bahl, H.C., Ritzman, L.P. and Gupta, J.N.D. (1987), "OR Practice-Determining lot sizes and resource requirements: A review", Operations Research, Vol. 35, No. 3, pp. 329-45. http://dx.doi.org/10.1287/opre.35.3.329.

Belvaux, G. and Wolsey, L.A. (1998), "Lot-sizing problems: Modelling issues and a specialized branch-andcut system BC-PROD", Constraints, Vol. 9849, pp. 1-34.

Belvaux, G. and Wolsey, L.A. (2003), "Modelling Practical Lot-Sizing Problems as Mixed-Integer Programs", Management Science, Vol. 47, No. 7, pp. 993-1007. http://dx.doi.org/10.1287/mnsc.47.7.993.9800.

Boulaksil, Y. (2016), "Safety stock placement in supply chains with demand forecast updates", Operations Research Perspectives. Elsevier Ltd, Vol. 3, pp. 27-31. http://dx.doi.org/10.1016/j.orp.2016.07.001.

Brahimi, N. (2004), Production planning: New lot-sizing models and algorithms, PhD thesis. ENS de Techniques Industrielles et des Mines de Nates.

Brahimi, N., Dauzere-Peres, S., Najid, N.M. et al. (2006), "Single item lot sizing problems", European Journal of Operational Research, Vol. 168, No. 1, pp. 1-16. http://dx.doi.org/10.1016/j.ejor.2004.01.054.

Brahimi, N., Absi, N., Dauzère-Pérès, S. et al. (2017), “Single-item dynamic lot-sizing problems: An updated survey", European Journal of Operational Research Elsevier B., Vol. 263, No. 3, pp. 838-63. http://dx.doi.org/10.1016/j.ejor.2017.05.008.

Brandimarte, P. (2006), "Multi-item capacitated lot-sizing with demand uncertainty", International Journal of Production Research, Vol. 44, No. 15, pp. 2997-3022. http://dx.doi.org/10.1080/00207540500435116.

Bude, B. (2008), Quantitative production planning model for ice cream production, Degree of Master of Science in Operations Management and Logistics, Eindhoven University of Technology.

Buschkühl, L., Sahling, F., Helber, S. et al. (2010), "Dynamic capacitated lot-sizing problems: A classification and review of solution approaches", OR-Spektrum, Vol. 32, No. 2, pp. 231-61. http://dx.doi.org/10.1007/s00291-008-0150-7.

Chan, F.T.S., Tibrewal, R.K., Prakash, A. et al. (2015), "A biased random key genetic algorithm approach for inventory-based multi-item lot-sizing problem", Proceedings of the Institution of Mechanical Engineers. Part B, Journal of Engineering Manufacture, Vol. 229, No. 1, pp. 157-71. http://dx.doi.org/10.1177/0954405414523594.

Chen, D.-S., Batson, R.G., Dang, Y. et al. (2011), Applied Integer Programming: Modeling and Solution, John Wiley \& Sons, New York. http://dx.doi.org/10.1002/9781118166000.

Cunha, A.L., Santos, M.O., Morabito, R. et al. (2018), "'An integrated approach for production lot sizing and raw material purchasing', European Journal of Operational Research", Elsevier B., Vol. 269, No. 3, pp. 923-38. http://dx.doi.org/10.1016/j.ejor.2018.02.042.

Díaz-madroñero, M., Mula, J. and Peidro, D. (2014) “A review of discrete-time optimization models for tactical production planning", Vol. 52, No. 17, pp. 5171-205. http://dx.doi.org/10.1080/00207543.2014.899721.

Drexl, A. and Haase, K. (1995), "Proportional lotsizing and scheduling", International Journal of Production Economics, Vol. 40, No. 1, pp. 73-87. http://dx.doi.org/10.1016/0925-5273(95)00040-U.

Erenay, B., Egilmez, G. and Süer, G.A. (2015) "Stochastic Capacitated Lot Sizing Subject to Maximum Acceptable Risk Level of Overutilization", in Proceedings of 26th Annual Production and Operations Management Society Conference, Athens, Ohio.

Erromdhani, R. and Rebaï, A. (2017), "MIP formulations and metaheuristics for Multi-Item capacitated lotsizing problem with non-customer specific production time windows and setup times", American Journal of Operations Research, Vol. 07, No. 02, pp. 83-98. http://dx.doi.org/10.4236/ajor.2017.72006. 
Ferreira, S.A., Neto, J.V. and Batista, H.M.C.S. (2019), "Critical success factors on project and process management in competitive strategy implementation", Brazilian Journal of Operations \& Production Management, Vol. 16, No. 4, pp. 605-16. http://dx.doi.org/10.14488/BJOPM.2019.v16.n4.a6.

Florim, W., Dias, P., Santos, A.S. et al. (2019), "'Analysis of lot-sizing methods' suitability for different manufacturing application scenarios oriented to MRP and JIT/Kanban environments"', Brazilian Journal of Operations \& Production Management, Vol. 16, No. 4, pp. 638-49. http://dx.doi.org/10.14488/BJOPM.2019.v16.n4.a9.

Glock, C.H., Grosse, E.H. and Ries, J.M. (2014), "The lot sizing problem: A tertiary study", International Journal of Production Economics, Vol. 155, pp. 39-51. http://dx.doi.org/10.1016/j.ijpe.2013.12.009.

Grillo, H., Mula, J., Martínez, S. et al. (2018), "Key parameters for the analysis stage of internationalization of operations", Brazilian Journal of Operations \& Production Management, Vol. 15, No. 2, pp. 173-81. http://dx.doi.org/10.14488/BJOPM.2018.v15.n2.a1.

Hatzikonstantinou, O., Athanasiou, E. and Pandelis, D.G. (2012), "Real-time production scheduling in a multi-grade PET resin plant under demand uncertainty", Computers \& Chemical Engineering, Vol. 40, pp. 191-201. http://dx.doi.org/10.1016/j.compchemeng.2012.01.011.

Hofer, C., Eroglu, C. and Rossiter Hofer, A. (2012), "The effect of lean production on financial performance: The mediating role of inventory leanness", International Journal of Production Economics. Elsevier, Vol. 138, No. 2, pp. 242-53. http://dx.doi.org/10.1016/j.ijpe.2012.03.025.

Hung, Y.F. and Hu, Y.C. (1998), "Solving mixed integer programming production planning problems with setups by shadow price information", Computers \& Operations Research, Vol. 25, No. 12, pp. 1027-42. http://dx.doi.org/10.1016/S0305-0548(98)00037-9.

Jang, J. and Chung, B. Do (2020), "Aggregate production planning considering implementation error: A robust optimization approach using bi-level particle swarm optimization", Computers and Industrial Engineering. Elsevier, Vol. 142, pp. 106367. http://dx.doi.org/10.1016/j.cie.2020.106367.

Jans, R. and Degraeve, Z. (2008), "Modeling industrial lot sizing problems: A review", International Journal of Production Research, Vol. 46, No. 6, pp. 1619-43. http://dx.doi.org/10.1080/00207540600902262.

Kallrath, J. (2000), "Mixed integer optimization in the chemical process industry: Experience, potential and future perspectives", ICHEME, Vol. 78, No. 7844, pp. 809-22. http://dx.doi.org/10.1205/026387600528012.

Kallrath, J. (2002), "Combined strategic and operational planning: An MILP success story in chemical industry", OR-Spektrum, Vol. 24, No. 3, pp. 315-41. http://dx.doi.org/10.1007/s00291-002-0102-6.

Karimi, B., Fatemi Ghomi, S.M.T. and Wilson, J.M. (2003), "The capacitated lot sizing problem: A review of models and algorithms", Omega, Vol. 31, No. 5, pp. 365-78. http://dx.doi.org/10.1016/S03050483(03)00059-8.

Karimi, B., Fatemi Ghomi, S.M.T. and Wilson, J.M. (2006), "A tabu search heuristic for solving the CLSP with backlogging and set-up carry-over", The Journal of the Operational Research Society, Vol. 57, No. 2, pp. 140-7. http://dx.doi.org/10.1057/palgrave.jors.2601968.

Kazan, C. (2018), An optimization model for the incorporation of the cultural environment in the aggregate production problem. MSc Thesis, Koc University.

Küçükyavuz, S. and Pochet, Y. (2009), "Uncapacitated lot sizing with backlogging: The convex hull", Mathematical Programming, Vol. 118, No. 1, pp. 151-75. http://dx.doi.org/10.1007/s10107-007-0186-5.

Liberopoulos, G., Kozanidis, G. and Hatzikonstantinou, O. (2010), "Production scheduling of a multi-grade PET resin plant", Computers \& Chemical Engineering, Vol. 34, No. 3, pp. 387-400. http://dx.doi.org/10.1016/j.compchemeng.2009.05.017.

Liu, X., Chu, F., Chu, C. et al. (2007), "Lot sizing with bounded inventory and lost sales", International Journal of Production Research, Vol. 45, No. 24, pp. 5881-94. http://dx.doi.org/10.1080/00207540600891408.

Loparic, M., Pochet, Y. and Wolsey, L.A. (2001), "The uncapacitated lot-sizing problem with sales and safety stocks", Mathematical Programming, Series B, Vol. 89, No. 3, pp. 487-504. http://dx.doi.org/10.1007/PL00011411.

Melega, G.M., de Araujo, S.A. and Jans, R. (2018), "Classification and literature review of integrated lotsizing and cutting stock problems', European Journal of Operational Research", Elsevier B., Vol. 271, No. 1, pp. 1-19. http://dx.doi.org/10.1016/j.ejor.2018.01.002. 
Péra, T.G., Bartholomeu, D.B., Su, C.T. et al. (2019), "Evaluation of green transport corridors of Brazilian soybean exports to China", Brazilian Journal of Operations \& Production Management, Vol. 16, No. 3, pp. 398-412. http://dx.doi.org/10.14488/BJOPM.2019.v16.n3.a4.

Pochet, Y. (2001) "Mathematical programming models and formulations for deterministic production planning problems", Lecture Notes in Computer Science (including subseries Lecture Notes in Artificial Intelligence and Lecture Notes in Bioinformatics), Vol. 2241, pp. 57-111. http://dx.doi.org/10.1007/3-54045586-8_3.

Pochet, Y. and Wolsey, L.A. (2006), Production Planning by Mixed Integer Programming, Springer, Berlin. http://dx.doi.org/10.1007/0-387-33477-7.

Rădăşanu, A.C. (2016) "Inventory Management, Service Level and Safety Stock", Journal of Public Administration, Finance and Law, Vol. 9, pp. 145-153.

Sung, C.S. and Chang, S.H. (1986), "A capacity-constrained single-facility multi-product production planning model", Journal of the Operations Research Society of Japan, Vol. 29, No. 3, pp. 232-45. http://dx.doi.org/10.15807/jorsj.29.232.

Teksan, Z.M. (2011), Integrated production planning, shift planning and detailed scheduling in a tissue paper manufacturer, Routledge, London. http://dx.doi.org/10.1080/01402390.2011.569130.

Tousain, R.L. and Bosgra, O.H. (2006), "Market-oriented scheduling and economic optimization of continuous multi-grade chemical processes", Journal of Process Control, Vol. 16, No. 3, pp. 291-302. http://dx.doi.org/10.1016/j.jprocont.2005.06.009.

Tsutsumi, D., Gyulai, D., Kovács, A. et al. (2020), "Joint optimization of product tolerance design, process plan, and production plan in high-precision multi-product assembly", Journal of Manufacturing Systems. Elsevier, Vol. 54, No. February, pp. 336-47. http://dx.doi.org/10.1016/j.jmsy.2020.01.004.

United States Environmental Protection Agency - EPA (2017), Sustainable Manufacturing. available at: https://www.epa.gov/sustainability/sustainable-manufacturing (accessed 25 July 2019).

Valencia, E. T., Lamouri, S., Pellerin, R. et al. (2019) “Production planning in the fourth industrial revolution: A literature review", IFAC-PapersOnLine. Vol. 52, No. 13, pp. 2158-63. http://dx.doi.org/10.1016/j.ifacol.2019.11.525.

Van Wassenhove, L. and De Bodt, M.A. (1983), "Capacitated lot sizing for injection moulding: A Case Study", The Journal of the Operational Research Society, Vol. 34, No. 6, pp. 489-501. http://dx.doi.org/10.1057/jors.1983.116.

Williams, P.H. (2013), Model Building in Mathematical Programming. John Wiley \& Sons, Hoboken.

Authors contribution: Demirkan, A.A.: Study and solution approach design; data collection; linear model establishment and solving; model validation and verification; writing. Unutmaz Durmuşoğlu, Z.D.: Study and solution approach design; supervision; model validation and verification; writing. 